\title{
The Potential Role of Naproxen in Promoting Rivastigmine Effect Against Aluminum Chloride- Induced Alzheimer-Like Model in Rats
}

\section{Raafat A. Abdel-Aal}

Assiut University Faculty of Medicine

Ola A. Hussein

Assiut University Faculty of Medicine

Reham G. Elsaady

Assiut University Faculty of Medicine

Lobna Abdelzaher ( $\sim$ Lobna@aun.edu.eg )

Assiut University Faculty of Medicine https://orcid.org/0000-0001-8438-7924

\section{Research Article}

Keywords: Alzheimer's disease, Naproxen, Behavior, Nestin, Rats

Posted Date: August 27th, 2021

DOI: https://doi.org/10.21203/rs.3.rs-831722/v1

License: (9) This work is licensed under a Creative Commons Attribution 4.0 International License. Read Full License 


\section{Abstract}

Alzheimer's disease (AD) is one of the leading causes of dependence and disability among the elderly worldwide. The traditional anti-Alzheimer medication, rivastigmine, one of the cholinesterase inhibitors (ChEls), fails to achieve a definitive cure. Neuroinflammation plays a central role in AD pathogenesis. We tested the hypothesis that naproxen, a non-steroidal anti-inflammatory drug (NSAID), administration to the rivastigmine-treated aluminum chloride ( $\mathrm{AlCl} 3$ ), Alzheimer's rat model, could provide an additive neuroprotective effect compared to rivastigmine alone. The studied groups were control (Cont), $\mathrm{AlCl}_{3}$ treated (Al), rivastigmine treated (RIVA), naproxen treated (Napro), and combined rivastigmine and naproxen treated (RIVA + Napro). Rats' memory, spatial learning, and cognitive behavior were assessed followed by evaluation of hippocampal acetylcholinesterase (AChE) activity. Hippocampal and cerebellar histopathology were thoroughly examined. A marker of astroglial injury; glial fibrillary acidic protein (GFAP), the apoptosis maker; activated caspase-3 and the neuroepithelial stem cells marker; nestin expressions were immunohistochemically assayed. AD rats displayed significantly impaired memory and cognitive function, augmented hippocampal AChE activity, massive neurodegeneration associated with enhanced astrogliosis, apoptosis, and impaired neurogenesis. Rivastigmine, naproxen, and their combination decreased hippocampal AChE activity, mitigated behavioral and neuropathological changes in Al-intoxicated rats, possibly through downregulation of activated caspase-3 and upregulation of nestin. Except for the enhancement of neurogenesis and suppression of apoptosis, the combination therapy had no additional neuroprotective benefit over rivastigmine-only therapy. Naproxen's efficacy was demonstrated by its ability to act at the cellular level, enhance neurogenesis, and suppress apoptosis without having an additional mitigating impact in Al-induced cognitive impairment.

\section{Introduction}

Alzheimer's disease (AD), a devastating age-related neurodegenerative disorder, is considered the most common cause of progressive dementia in the elderly above 65 (Reddy et al. 2020). It is manifested by memory impairment besides behavioral and personality changes and various cognitive deficits (Reddy et al. 2020). AD imposes a severe financial, mental and physical burden upon patients and their caregivers (Leifer 2003). Early intervention can help the preservation of neural structures; delay the onset of dementia and disease progression.

The neuropathological changes of the AD brain include intracellular neurofibrillary tangles (NFTs) of hyper-phosphorylated tau, extracellular amyloid plaques, and vascular deposits (Villemagne et al. 2013). They were particularly identified in the hippocampus, cerebral cortex (Villemagne et al. 2013), the molecular, granular, and Purkinje cell layers of the cerebellar cortex (Singh-Bains et al. 2019). Amyloid- $\beta$ $(A \beta)$ proteins, the principal component of senile plaques, play a crucial role in neurodegeneration (Nhan et al. 2015). Accumulating evidence reveals the critical role of $A \beta$-induced caspase- 3 activation in neuronal apoptosis (Kim et al. 1997; Harada and Sugimoto 1999; Allen et al. 2001) still before amyloid plaques and NFTs formation (LaFerla et al. 1997; Guo et al. 1998). 
Neurofibrillary degeneration of forebrain cholinergic neurons, a significant characteristic of AD, contributes to memory and attention deficits (Ferreira-Vieira et al. 2016). ChEls such as tacrine, donepezil, rivastigmine, galantamine is, therefore, the currently approved drugs (Ray and Lahiri 2009; Nazem et al. 2015). However, they have failed to delay or prevent the progression of the disease; provided mild symptomatic benefits (Yiannopoulou et al. 2019).

Recent studies have uncovered the role of neuroinflammation and aberrant gliosis in AD (Imbimbo et al. 2010). Microglia, the primary immune cells of the central nervous system (CNS), can bind $A \beta$ and trigger sustained low-grade neuroinflammation that contributed to altered neuronal integrity (Liddelow et al. 2017) and enhanced $A \beta$ production (Hu et al. 1998; Nhan et al. 2015; Zhu et al. 2018).

Remarkably, neurogenesis occurs until the end of life in cognitively healthy people but declines significantly as AD pathology takes hold (Moreno-Jiménez et al. 2019). Impaired hippocampal neurogenesis is considered one of the major players in cognitive/memory dysfunctions in AD (Hollands et al. 2016). Nestin, an intermediate filament protein and a marker of multipotent neural stem cells (NSCs) (Goldman 2006), has induced neurogenesis in nigral dopaminergic neurons in the mouse model of Parkinson's disease (PD) (Albright et al. 2016). However, its implication in AD is still controversial (Yu et al. 2018; Li et al. 2019). Therapeutic approaches targeting inflammation could manipulate ADassociated impaired neurogenesis (Sung et al. 2020).

Numerous observational studies have elucidated NSAIDs' role in reducing or delaying the progression of $A D$ (Spangenberg and Green 2017). Moreover, decreased incidence of $A D$ was reported in patients taking long-term NSAIDs for rheumatoid arthritis (Jenkinson et al. 1989; Kinney et al. 2018; Zhu et al. 2018). NSAIDs increased lysosomal activity, reduced cerebral plaque load, and, therefore, improved spatial learning and memory (Chandra et al. 2018). Ibuprofen and naproxen has prevented the impaired neurogenesis in AICD transgenic mice (Ghosal et al. 2010). Moreover, subsets of NSAIDs can prevent apoptosis through partially depolarizing mitochondria and preventing $\mathrm{Ca}^{2+}$ overload (Sanz-Blasco et al. 2008).

Naproxen, a member of non-selective NSAIDs, has been tested for its neuroprotective effect against AD in the elderly (Martin et al. 2008). It has restored memory function and prevented A $\beta$-mediated inhibition of long-term hippocampal plasticity (LTP) in the AD transgenic mice model (Kotilinek et al. 2008).

We aimed to study the hypothesis that naproxen, when combined with rivastigmine, could have an additive neuroprotective effect in the $A D$ rat model, which could be related to modifications in neuronal turnover, apoptosis, and neurogenesis. Of all Alzheimer's models, AlCl3-induced brain pathology is more applicable to the sporadic form, the more prevalent type accounting for $95 \%$ of all cases (Li et al. 2016). Naproxen potential mitigating effect was investigated through evaluating rats' behavior, hippocampal AChE activity, hippocampal and cerebellar histopathological changes besides investigating neurogenesis and apoptosis markers expression in rivastigmine-treated AlCl3 Alzheimer's rat model. 


\section{Materials And Methods \\ 2.1. Animals and Experimental design}

All the animal procedures were conducted with approval from the institutional Animal Care, and Use Committee of the Faculty of Medicine, Assiut University (IRB no:17100383) and could be given by request. They were carried out following the internationally accepted principles for laboratory animal use and care the US guidelines (NIH publication \#85 - 23, revised in 1985). Every effort has been made to reduce the number of animals used and their suffering. Adult male Albino Wistar rats weighing 180-220 $\mathrm{g}$ were purchased from the animal house of the Faculty of Medicine, Assiut University. They were housed in stainless steel cages in a well-ventilated room under a 12-h light/dark cycle. Rats had access to water and food ad libitum. Rats were randomly divided into five groups $(n=10)$ :

Group 1; Cont group received daily saline injections intraperitoneal (IP) for 60 days.

Group 2; Al group received $\mathrm{AlCl}_{3}$ hexahydrate (qualikemes India), dissolved in saline, daily IP at a dose of $80 \mathrm{mg} / \mathrm{Kg}$ per injection for 60 days (Abdel-Aal et al. 2011).

Group 3; RIVA group received $\mathrm{AlCl}_{3}$ and rivastigmine (reference standard drug) (Beijing Mesochem Technology co., Ltd.), dissolved in sterile water, daily IP at a dose of $1 \mathrm{mg} / \mathrm{kg}$ per injection for six weeks starting two weeks before $\mathrm{AlCl}_{3}$ administration (Ismail et al. 2013; Zhou et al. 2016).

Group 4; Napro group received $\mathrm{AlCl}_{3}$ and naproxen (Pharm Bio-Tech co., Ltd.), dissolved in saline, daily at a dose of $20 \mathrm{mg} / \mathrm{kg}$ per injection IP for two weeks concurrently with $\mathrm{AlCl}_{3}$ (Teng et al. 2011; Sil et al. 2014).

Group 5; RIVA + Napro group received $\mathrm{AlCl}_{3}$, rivastigmine $(1 \mathrm{mg} / \mathrm{kg}$ for six weeks starting two weeks before $\mathrm{AlCl}_{3}$ administration), and naproxen (20 mg/kg for two weeks concurrently with $\mathrm{AlCl}_{3}$ ).

\subsection{Behavioral studies}

A battery of behavioral paradigms was performed in the following sequence; NOR and PA tests.

\subsubsection{Novel Object Recognition (NOR) test}

The test aims to assess the exploratory behavior, memory, and object recognition based on the intrinsic affinity of rodents to privilege exploring novel objects over familiar ones. The test was carried out in a room illuminated by a ceiling-oriented halogen lamp that gives a uniform dim light. NOR test apparatus is a square stainless steel open field box $(60 \times 60 \times 40 \mathrm{~cm})$ with black walls and floor. NOR test objects were distinct in shape and color and made of heavily painted wood that rats could not displace. They were about $15 \mathrm{~cm}$ in height. The test box and objects were cleaned with $70 \%$ ethyl alcohol between trials to exclude behavioral tasks associated with olfactory cues. Rats were placed in the experimental room for at least $30 \mathrm{~min}$ before testing. They were habituated to the empty test box for $10 \mathrm{~min}$ per day for two 
consecutive days. A learning session was conducted by placing each rat in the test box with two identical objects for the amount of time necessary to spend a total of $15 \mathrm{sec}$ exploring these two objects to exclude the possibility of random preference. Exploration was considered when, within a cut-off period of $4 \mathrm{~min}$, the rat was touching, looking at, or sniffing with its head within $2 \mathrm{~cm}$ of the object. Rats exploring both objects for less than $15 \mathrm{sec}$ were excluded from the experiment. Following the learning phase, three testing sessions were conducted after a retention interval of $5 \mathrm{~min}, 2 \mathrm{hrs}$, and $24 \mathrm{hrs}$ to assess short, intermediate, and long-term memories, respectively. Rats were allowed 3 min exploration of one of the objects previously seen during the learning phase and another novel object. Rats with a low level of object exploration, time spent exploring novel and familiar objects $<5 \mathrm{sec}$, were excluded. As the standard calculation for NOR, memory performance was measured by measuring the recognition index (RI), (time spent exploring the novel object) / (total time spent exploring both objects) $* 100$ (Antunes and Biala 2012).

\subsubsection{Passive avoidance (PA) test}

The PA test is fear-motivated carried out in rodent models of CNS disorders to assess learning and memory. It is based on the interaction between aversive stimulation, mild foot shock, and a particular environmental situation. The apparatus consists of two chambers separated by a wall containing an 8 $\mathrm{cm}$ communicating hole. A single chamber was kept illuminated. The test was performed on two consecutive days. On the first day, rats were individually positioned in the illuminated chamber. Once they reached the dark chamber, an electrical shock was applied to their feet via the floor grid. 24 hrs later, rats were placed again in the illuminated chamber, and the interval till entry to the dark one was recorded; step-through latency (Abdel-Aal et al. 2011).

\subsection{Acetylcholinesterase (AChE) activity}

After carrying out all the behavioral experiments, the animal groups were sacrificed, and their brains were carefully isolated. Hippocampi were weighed, homogenized in phosphate buffer saline (PBS), centrifuged for $5 \mathrm{~min}$ at $5000 \times \mathrm{gg}$, and the supernatant was collected. According to the manufacturer's protocol, the hippocampal AChE activity was determined using ELISA kits (Elabscience Co.). The optical density (OD) was measured at a wavelength of $450 \mathrm{~nm}$ using a microplate reader after the enzyme-substrate reaction was terminated. The AChE activity was determined by comparing the OD of the samples to the standard curve.

\subsection{Histopathological studies}

Rats were anesthetized with thiopental sodium (50 mg/kg) IP (Abdi-Azar and Maleki 2014) at the end of the experiment. Their hearts were exposed and transcardially perfused through the left ventricle with saline till getting clear flow, then finalized with $10 \%$ formalin. Hippocampal and cerebellar tissues were dissected out and processed for light microscopy and immunohistochemical staining techniques. Some sections were stained with hematoxylin \& eosin (Hx\&E) for general histopathological examination (Bancroft and Gamble 2008).

\subsection{Immunohistochemistry Studies}


The isolated hippocampi and cerebellar tissues were fixed in $10 \%$ neutral formalin followed by dehydration, clearing, and paraffin embedding. Paraffin sections were cut and incubated at $4^{\circ} \mathrm{C}$ overnight with the following primary antibodies; anti-GFAP; Ab-1 (Clone GA-5) mouse monoclonal antibody (1:100) (Thermo Fisher Scientific Co, Fermont, California, USA), rabbit antimouse caspase-3 polyclonal antibody (1:100) (Chongqing Biospes co., Ltd. China), mouse monoclonal anti-nestin antibody (Abcam, ab22035, UK) (1:100). After that, sections were stained with an avidin-biotin-peroxidase system with diaminobenzidine as the chromogen (DAKO (HRP; rabbit/mouse/goat (DAB+) code no. K0679; Dako Cytomation) in line with the instructions for the staining procedure contained in the Dako LSAB + SystemHRP. Hematoxylin was used to counterstain the sections after they were washed in distilled water.

For negative control staining, some sections were incubated with PBS instead of the primary antibody. In these parts, no immunoreactivity was found.

\subsection{Morphometric Studies}

Morphometric studies were conducted using a Java-based open-source image processing package, image $\mathrm{J}$. The required parameters were measured in 3 non-overlapped fields $/ 5$ sections $/ 3$ rats from each group. The measured parameters in Hx\&E-stained sections were; 1 ) the number of dark cells in CA1 fields of the hippocampi and 2) the number of dark cells in Purkinje cell layers of the cerebellar tissues using X40 lens. The measured parameters in immunostained sections were; 1$)$ the number of caspase-3 (+ve) immunostained cells in CA1 fields, 2) the number of caspase-3 (+ve) immunostained cells in Purkinje cell layers, and 3 ) the number of nestin (+ve) immunostained cells in cerebellum using X40 lens.

\subsection{Electron Microscopy Studies}

The isolated hippocampi and cerebellar tissues were dissected out with the aid of a dissecting microscope, fixed in glutaraldehyde, and processed for transmission electron microscopy. Semi-thin sections $(0.5-1 \mu \mathrm{m})$ were stained with toluidine blue. Ultrathin sections (500-800A), for the selected areas in semi-thin sections, were contrasted with uranyl acetate and lead citrate, examined with the transmission electron microscope (TEM) JEOL (JEM-100 CXII, Tokyo, Japan), and photographed at $80 \mathrm{kV}$ in Assiut University-Electron Microscope Unit.

\section{Statistical analysis}

Data were expressed as mean \pm standard error of the mean (SEM). Statistical analysis was performed by multiple t-tests, one-way and two-way repeated-measures ANOVA, followed by post hoc Tukey's test when appropriate. All statistical tests were directed using GraphPad Prism 7 software. The difference among groups was considered significant for $p<0.05$.

\section{Results}

\section{1 behavioral outcomes}




\subsubsection{Novel Object Recognition (NOR) test}

The time is taken to explore a novel object at $5 \mathrm{~min}, 2 \mathrm{hrs}$, and $24 \mathrm{hrs}$ was substantially longer than that of the familiar one in the Cont group. Poor memory performance was observed in the Al group, detected as lack of preference for a novel object relative to the Cont group ( $p<0.01,5 \mathrm{~min} ; 2 \mathrm{hrs} ; p<0.05,24 \mathrm{hrs})$ (Fig. 1). The RIVA group spent considerably more time investigating the novel object compared to the Al group ( $p<0.05,5 \mathrm{~min} ; 2 \mathrm{hrs} ; 24 \mathrm{hrs}$ ) (Fig. 1). Treatment with naproxen substantially improved the time spent investigating the novel object at the specified time points ( $p<0.01,5 \mathrm{~min} ; 2 \mathrm{hrs} ; p<0.05,24 \mathrm{hrs}$ ) (Fig. 1), reflecting its ability to rescue memory deficit in the AD rat model. The RIVA + Napro group did not show any additive effect than the RIVA group (Fig. 1).

\subsubsection{Passive avoidance (PA) test}

Al group showed a significant decrease in step-through latency than the Cont group $(p<0.01)$, signifying marked cognitive deficits. RIVA and Napro groups exhibited a significant increase in step-through latency than the Al group $(p<0.05, p<0.01)$, reflecting improvement in learning and memory tasks. There were no significant differences in retention latency time between RIVA + Napro and RIVA groups (Fig. 2).

\subsection{Acetylcholinesterase (AChE) activity}

AChE activity was evaluated in the hippocampi of the studied groups. Hippocampal AChE activity was significantly enhanced, an indication of cholinergic impairment, in the Al group when compared to the Cont group $(p<0.01)$ (Fig. 3). RIVA and Napro groups dramatically reduced hippocampal AChE activity compared to the Al group $(p<0.05, p<0.01)$ (Fig. 3). Compared to the RIVA group, the RIVA + Napro group showed a non-significant change in hippocampal AChE activity (Fig. 3).

\subsection{Histopathological studies}

Examination of Hx\&E stained sections of the Cont group brain revealed the normal structure of the rat hippocampus. It was formed of an outer blade (Ob) and an inner blade (Ib) of the dentate gyrus (DG), CA1, CA2, and CA3 fields of Ammon's horn (AH) (Fig. 4a). Cont CA1 field showed stratum oriens (SO), stratum pyramidal (SP), and stratum radiatum (SR) that extended from the alveus to the hippocampal fissure (Fig. 4a). The pyramidal neurons (P), the principal cell type in the CA1 field, were characterized by their triangular perikarya, medium-sized round vesicular nuclei $(\mathrm{N})$, and basophilic cytoplasm. Their processes extended to SR (Fig. 4b). The Al group showed multiple intensely stained irregular pyramidal neurons surrounded by empty spaces (Fig. 4c). Most pyramidal neurons (P) appeared normal with round vesicular nuclei $(\mathrm{N})$, yet few cells still seemed irregular and deeply stained in the RIVA group (Figs. 4d, 4e). Some pyramidal neurons $(P)$ seemed regularly shaped with round vesicular nuclei in the RIVA + Napro group (Fig. 4f). Our morphometric results revealed a significant increase in the number of dark cells ( $p<$ 0.0001) in the Al group compared to the Cont group; however, a significant decrease in their numbers was observed in the treated groups (Fig. 4g). The RIVA + Napro combination showed a significant decrease in the number of dark cells compared to the RIVA group $(p<0.001)$ (Fig. $4 \mathrm{~g}$ ). Hx\&E stained sections of the cerebellar cortex were examined. Cont group cerebellar cortex was composed of an outer molecular layer 
(OL), a middle Purkinje cell layer (PL), and an inner granule cell layer (GL) (Fig. 5a). The granule cell layer was packed with granule cells with round nuclei and separated by small acidophilic areas, the cerebellar glomeruli (Fig. 5a). The Purkinje cell layer consisted of one layer of large flask-shaped Purkinje cells with a large central vesicular nucleus (Fig. 5a). The Purkinje cell layer was the most affected as most cells were shrunken deeply stained, leaving empty spaces in the Al group (Fig. 5b). Most Purkinje cells attained their regular flask-shaped appearance with large vesicular nuclei, while few cells were still irregularshaped and deeply stained in RIVA, Napro, and RIVA + Napro groups (Figs. 5c-5e). Treated groups displayed a significant decrease in the number of dark-stained Purkinje cells $(p<0.0001)$ compared to the Al group (Fig. 5f). Compared to the RIVA group, the RIVA + Napro group had no additive effect (Fig. 5f).

\subsection{Immunohistochemical Studies}

\subsubsection{GFAP expression (hippocampus; CA1 field)}

High expression of GFAP is associated with astrocyte activation, which can contribute to brain injury. GFAP immunostained sections of the Cont group showed few immunostained short processed glial cells (Fig. 6a). On the contrary, a marked increase in long processed GFAP immunostained cells in all layers of CA1 fields was displayed in Al, RIVA, Napro, and RIVA + Napro groups (Figs. 6b-6e).

\subsubsection{Active caspase-3 expression (hippocampus; CA1 field $\&$ cerebellar cortex; Purkinje cell layer)}

\section{\# Hippocampus; CA1 field}

Caspases-3 is one of the most important proteases involved in the caspase cascade that leads to apoptosis. Cont group revealed few caspase-3 (+ ve) immunostained cells (Fig. 7a). There was a significant increase in caspase-3 (+ve) immunostained cells in the Al group (Fig. 7b). Caspases-3 (+ve) immunostained cells were significantly reduced in the RIVA, Napro, and RIVA + Napro classes (Figs. 7c7e). In the Al group, morphometric findings showed a substantial increase in caspase-3 (+ ve) immunostained cells $(p<0.0001)$. In contrast, treated groups showed a significant reduction in caspase-3 $(+v e)$ immunostained cells $(p<0.0001)$ compared to the Al group. Caspase- 3 expression was significantly lower in the RIVA + Napro group relative to the RIVA group $(p<0.05)$ (Fig. $7 f)$, indicating that naproxen provided an extra neuroprotective effect when concurrently administered with rivastigmine compared to rivastigmine only therapy.

\section{\# Cerebellar cortex; Purkinje cell layer}

Cont group immunostained sections showed few caspase-3 (+ve) immunostained cells (Fig. $7 \mathrm{~g})$. Al group, however, revealed increased caspase-3 (+ ve) immunostained cells (Fig. 7h). On the contrary, a marked reduction in caspase-3 (+ ve) immunostained cells were detected in RIVA, Napro, and RIVA+ Napro groups (Figs. 7i-7k). Statistical analysis revealed a significant increase in caspase-3 (+ ve) 
immunostained cells in the Al group $(p<0.0001)$ compared to the Cont group. In contrast, a significant decrease in caspase $-3(+v e)$ immunostained cells was noticed in treated groups $(p<0.0001)$ compared to the Al group (Fig. 7l). Yet, the combination therapy did not provide extra benefit to rivastigmine monotherapy.

\subsubsection{Nestin expression (Cerebellar cortex; granule cell layer )}

Decreased nestin (+ve) immunostained cells were observed in the Al group (Fig. 8b) relative to the Cont group (Fig. 8a), indicating impaired neurogenesis in the granule cell layer of the cerebellar cortex. RIVA, Napro, and RIVA + Napro groups showed increased nestin (+ ve) immunostained cells (Figs. 8c-8e) compared to the Al group indicating enhanced neurogenesis. Statistically, a significant reduction in nestin $(+\mathrm{ve})$ immunostained cells were observed in the Al group $(p<0.0001)$ compared to the Cont group. Napro group displayed a non-significant enhancement in nestin expression compared to the Al group (Fig. 8f). The RIVA and RIVA + Napro groups showed a substantial increase in nestin (+ve) immunostained cells relative to the Al group ( $p<0.01, p<0.0001)$ (Fig. 8f). The combination, however, exerted an additive effect relative to rivastigmine alone $(p<0.01)$ (Fig. 8f).

\subsection{Electron microscopy studies}

\section{\# Hippocampus (CA1 field; pyramidal cells \& astrocytes)}

The pyramidal neurons of the Cont group revealed normal fine structure (Fig. 9a); within abundant cytoplasm that contained mitochondria, rough endoplasmic reticulum (rER), and large ribosomes, they had large round nuclei with finely dispersed chromatin (Figs. 9a, 9b). The Cont astrocyte showed a regular oval euchromatic nucleus and minimal electrolucent cytoplasm enclosing mitochondria and ribosomes (Fig. 9h). Al group, most pyramidal neurons tended to have rarified cytoplasm (Fig. 9c), while others looked degenerated electron dense with ill-defined nuclei (Fig. 9d). Astrocytes had electrolucent swollen rarified cytoplasm (Fig. 9i). The RIVA group showed regenerated pyramidal neurons with electrolucent cytoplasm and large round euchromatic nuclei (Fig. 9e). Some cells were electrolucent with euchromatic nuclei in the Napro group, while others looked degenerated and electron-dense (Fig. 9f). Some pyramidal neurons appeared regenerated with electrolucent cytoplasm and euchromatic nuclei in RIVA + Napro (Fig. 9g); nevertheless, astrocytes still attained swollen rarified cytoplasm (Fig. 9j).

\section{\# Cerebellar cortex (granule cell layer \& Purkinje cells)}

Cont group granule cells were seen in clusters in the granule cell layer (Fig. 10a). Their nuclei appeared oval or rounded, surrounded by minimal electrolucent cytoplasm that enclosed few mitochondria and ribosomes (Fig. 10a). Purkinje cells were large-sized with large euchromatic nuclei surrounded by voluminous cytoplasm that enclosed abundant mitochondria, rER, and ribosomes (Fig. 10f). Al granule cells tended to have heterochromatic nuclei and electron-dense rarified cytoplasm (Fig. 10b). Purkinje 
cells perikaryon appeared degenerated electron dense with ill-defined nuclei and organelles (Fig. 10g), while others seemed electron-dense and surrounded by swollen astrocytic processes (Fig. 10h). Normal fine structure of granule cells was attained in the treated groups (Figs. 10c-10e). Purkinje cells appeared less electron-dense with a well-defined nucleus and abundant cytoplasm rich in organelles in the RIVA group (Fig. 10i). In contrast, some Purkinje cells in the Napro group were still electron-dense with illdefined nuclei and organelles (Fig. 10j). Purkinje cells had abundant electrolucent cytoplasm with large euchromatic nuclei surrounded by swollen astrocytic cytoplasm in the RIVA + Napro group (Fig. 10k).

\section{Discussion}

Our research was the first to show that naproxen could have an additive neuroprotective effect in the AlCl3-induced Alzheimer's rat model when given simultaneously with rivastigmine, the standard antiAlzheimer medication, by altering neuronal turnover, enhancing neurogenesis, and suppressing apoptosis. Naproxen has mitigated AlCl3-mediated neurocognitive deficit as evidenced by improved memory performance in the NOR test and reduced step-through latency in the PA test, besides ameliorating cholinergic deficits through decreased hippocampal AChE activity. Compared to rivastigmine alone, naproxen had no additional ameliorative influence on AD-related neurocognitive deficits when given synchronously with rivastigmine.

$A D$ is an irreversible debilitating age-related neurologic disorder affecting over 47 million people worldwide. It is one of the most disappointing medical concerns that greatly distress societies and their economy (Colucci et al. 2014; Liu et al. 2014), especially as the population ages globally (Caselli et al. 2006; Arshavsky 2010). The disease hallmark is an insidious progressive intellectual decline that commonly involves the memory of recent facts, executive functions, and spatial orientation (Benedikz et al. 2009). Speech, mobility, and neuropsychiatric problems are among the patients' sufferings (Sun et al. 2013). Therefore, timely diagnosis plus achieving effective therapeutic approaches are mandatory.

$A D$ is classically characterized by $\beta$-amyloid plaque deposits of $A \beta$ peptides, activated microglia, reactive astrocytes, and NFTs (Beach et al. 1989; Iqbal and Grundke-lqbal 2008; Weller and Budson 2018). $A \beta$ brain aggregation, mediated through imbalance between their production and clearance, provokes subsequent pathological events as oxidative stress and neuroinflammation that eventually lead to neuronal loss (Mawuenyega et al. 2010; Mucke and Selkoe 2012; Liu et al. 2016). Activated microglia and reactive astrocytes, tightly associated with amyloid plaques (Olabarria et al. 2010), augment the local inflammatory response (Nagele et al. 2003; Rodríguez et al. 2009).

Memory and cognitive decline are directly correlated with cerebral cholinergic neuron degeneration within the basal forebrain (Whitehouse et al. 1981, 1982). Decreased acetylcholine (ACh) release, impaired choline acetyltransferase action, or increased activity of AChE further aggravate Ach scarceness in AD (Fishman et al. 1986; Hammond and Brimijoin 1988; Rodríguez-Puertas et al. 1994). NMDA (N-methyl-Daspartate) receptors overactivation is fundamental for AD progression (Dingledine et al. 1999). ChEls as 
tacrine, donepezil, rivastigmine, and galantamine (Ray and Lahiri 2009; Nazem et al. 2015) for mild to moderate circumstances and NMDA antagonists as memantine for moderate to severe cases are the currently approved therapy. They can only provide symptomatic relief, despite being partly effective in the early stages (Citron 2010; Alteri and Guizzaro 2018). The standard anti-Alzheime drug, rivastigmine (Birks and Evans 2015; Kandiah et al. 2017), can enhance intellectual functioning through raising synaptic ACh levels mainly within the hippocampus and neocortex (Gothwal et al. 2019).

A potential association between $A D$ incidence and aluminum (Al) content in drinking water has been indicated (McLachlan et al. 1996; Altmann et al. 1999; Gauthier et al. 2000; Peder Flaten 2001; Exley and Esiri 2006). An elevated concentration of Al was detected in AD patients' brains (Crapper et al. 1973). Al industry personnel serving in miners, foundry, and welders have displayed impaired cognitive functions (Rifat et al. 1990; Polizzi et al. 2002; Giorgianni et al. 2003). Excess Al intake induces amyloid-beta precursor protein (APP) overexpression, amyloid deposition (Castorina et al. 2010), apoptosis activation besides degenerative neuronal changes (Crapper et al. 1973; Zatta et al. 2003; Kawahara and KatoNegishi 2011).

Divergent aspects of $A D$ have been studied through numerous categories of animal models. Rats are considered the favored species (Benedikz et al. 2009) as they are brainy, quick learners besides their similarities in physiological processes (Benedikz et al. 2009) and pathological alterations to human beings (Herrera et al. 1999; Reid et al. 2001; Hörsten et al. 2003; Loeffler 2004). We, therefore, decided to study the $\mathrm{AlCl} 3$ induced Alzheimer rat model as it is the most relevant to the sporadic AD pathology (Evrard et al. 1998; Li et al. 2016). Chronic AlCl3 administration enhances Al CNS access through the blood-brain barrier (BBB) via special high-affinity transferrin receptors (Roskams and Connor 1990). Al accumulates in all rat brain areas (Abubakar et al. 2004; Sakamoto et al. 2004; Kaur and Gill 2006), although the cerebral cortex, the hippocampus, and the cerebellum are the structures most commonly implicated in the lesions initiated by Al intoxication (Slanina et al. 1984; Misawa and Shigeta 1992). Our study showed significant neuronal degeneration presented as marked shrunken dark basophilic neurons with infiltration of glial cells within the CA1 pyramidal layer in the Al group, consistent with previous studies (Junior et al. 2013; Said and Rabo 2017; Bazzari et al. 2019). A significant increase in the deeply stained neurons within the Purkinje cell layer associated with electron-dense cytoplasm, illdefined nuclei, and organelles within the Purkinje and granular cell layers were displayed within Al group cerebellar tissues. Our findings are in line with other studies (Bhalla and Dhawan 2009; Bondy 2016) that revealed disorganization in the architecture of the Purkinje cell layer with a loss of Purkinje cells of cerebellar cortex in the AD rat model. RIVA group revealed the more or less normal histological structure of the hippocampus CA1 field and cerebellum Purkinje cell layer with a substantial reduction in the number of dark or deeply stained cells that is in line with other research (Mahdy et al. 2012), confirming the mitigating impact of rivastigmine on $\mathrm{AlCl} 3$-induced neurotoxicity.

AlCl3 AD rat model displayed a biphasic response of AChE activity; an increase in AChE activity in shortterm administration followed by pronounced decay of the enzyme activity on long-term (Kumar 1998; Kaizer et al. 2008). Long-term response ensues by a slow accumulation of Al with the formation of a 
complex with the anionic site of the AChE enzyme (Kumar 1998; Kaizer et al. 2008; Nampoothiri et al. 2015). In agreement with other studies (Zheng et al. 2009; Said and Rabo 2017), our findings revealed a significant increase in hippocampal AChE activity in the Al group indicating short phase response. Following previous research (Onor et al. 2007; Nampoothiri et al. 2015, 2017), our study showed that rivastigmine inhibited $\mathrm{AICl} 3$-enhanced hippocampal $\mathrm{AChE}$ activity, which partially enhanced cholinergic neurotransmission. In advanced cases, however, rivastigmine exerts its action by inhibiting BuChE activity (Greig et al. 2001; Giacobini et al. 2002).

AlCl3-treated animals have demonstrated major memory and cognitive deficits (Ikram et al. 2020; Mustafa 2020). They showed increased retention latency and decreased RI percentage (Jangra et al. 2015), indicating decreased short, intermediate, and long-term memory. Intracerebral administration of AlCl3 triggered learning deficits in rabbits as well (Rabe et al. 1982). The NOR test revealed that the Al group had a week exploratory preference compared to the Cont group and degradation in spatial and retention memory as measured by PA test, which is consistent with previous literature (Lakshmi et al. 2015).

Rivastigmine attenuated AlCl3-induced spatial and retention memory deficit (Mehrabadi et al. 2020). Decreased escape latency and increased discrimination index were reported in the streptozotocin rat model of AD treated with rivastigmine (Akhtar et al. 2020). Moreover, rivastigmine exerted positive effects on learning and memory in the chronic d-galactose-induced accelerated aging rodent model (Chogtu et al. 2018). It reversed spatial learning deficits induced by scopolamine as well (Deiana et al. 2009).

Neuroinflammation is acknowledged as a prominent feature in AD pathology (Hensley 2010). A $\beta$ directly activates glial cells, astrocytes and microglia, found near A $\beta$ plaques (Perlmutter et al. 1992; Townsend and Praticò 2005; Schwab and McGeer 2008; Heneka et al. 2015), triggering the release of inflammatory mediators, notably IFNy, IL-1 $\beta$, TNF-a, IL-6, TGF- $\beta$ (Constam et al. 1992; McGeer and McGeer 1995; Hu et al. 1998; Johnstone et al. 1999), free radicals, inducible nitric oxide synthase (iNOS) and nitric oxide (NO) (Hu et al. 1998; Ayasolla et al. 2004; Garção et al. 2006; Furman et al. 2012; Cai et al. 2014). It is believed that reactive astrogliosis, hypertrophy of cell soma, and processes induced by $A \beta$ plays a role in limiting the build-up of $A \beta$ plaques (Olabarria et al. 2010; Hou et al. 2011) through the expression of type III intermediate filament (IF) protein; glial fibrillary acidic protein (GFAP) (Wilhelmsson et al. 2006; Kamphuis et al. 2012). On the contrary, astrogliosis could enhance neurotoxicity with further neuronal death (Scuderi et al. 2014). Its role, therefore, in AD is still controversial. Nevertheless, astrogliosis degree is usually correlated with cognitive decline in AD (Beach and McGeer 1988; Mrak et al. 1996; Kashon et al. 2004).

Our study detected an apparent increase in hippocampal GFAP immunoreactivity in AlCl3-intoxicated rats suggesting severe astrocytic activation induced by Al uptake. Our results are consistent with those of other studies (Guo-ross et al. 1999; Li et al. 2009; Erazi et al. 2010; Justin-Thenmozhi et al. 2018), which detected increased GFAP immunolabelling in the hippocampus and frontal cortex after chronic Al intoxication in rats and rabbits (Yokel and Callaghan 1998) though unchanged GFAP immunoreactivity 
was still reported (Platt et al. 2001). Other studies, on the contrary, revealed a decrease in GFAP immunoreactivity, reflecting astrocytes' susceptibility to Al-induced neurotoxicity (Guo-ross et al. 1999; Junior et al. 2013). RIVA group showed enhanced GFAP immunoreactivity indicating persistent astrogliosis, which contradicts other studies (Mohamed et al. 2016) that displayed reduced immunoreactivity by $45-50 \%$. Similarly, rivastigmine has attenuated the memory decline in T2DM-AD model mice by suppressing gliosis (Matsuda and Hisatsune 2017). The diversity of the AD models may lie behind the conflicting outcomes.

Microglia were studied to play dual roles in A $\beta$ pathogenesis (Ard et al. 1996; Grathwohl et al. 2009; Majumdar et al. 2011). Early microglial recruitment enhances $A \beta$ clearance across the BBB via microglia scavenger receptors (Khoury et al. 1996; Paresce et al. 1996; Kunjathoor et al. 2004; Alarcón et al. 2005; Yang et al. 2011). Chronic inflammation, however, mediates microglial dysfunction, which plays a detrimental effect via the release of cytotoxic molecules, enhanced production, and impaired clearance of A $\beta$ (Hickman et al. 2008; Brandenburg et al. 2010; Feng et al. 2011). This is likely mediated by decreased expression of enzymes that degrade $A \beta$; insulysin, neprilysin, and metallopeptidase 9 matrix (MMP9); and loss of functional and structural integrity BBB (Hickman et al. 2008; Brandenburg et al. 2010; Feng et al. 2011).

$A$ vicious cycle of inflammation has been collectively designed between $A \beta$ accumulation, activated microglia, and microglial inflammatory mediators. Therefore, a therapeutic intervention targeting neuroinflammation, particularly in early disease processes (McGeer et al. 1996; Stewart et al. 1997; Vlad et al. 2008), seems to potentially restrain AD's further progression. NSAID use is associated with a lower risk of developing $A D$ in a range of ethnodemographic populations (Breitner et al. 1995; Stewart et al. 1997; Veld et al. 2001; Landi et al. 2003; Fischer et al. 2008; Szekely et al. 2008; Vlad et al. 2008; Côté et al. 2012) besides various preclinical studies (Lim et al. 2000; Weggen et al. 2001; Yan et al. 2003). Importantly, a greatly reduced risk of AD was noticed in rheumatoid arthritis patients on long-term NSAIDs (Mcgeer et al. 1990). Moreover, chronic therapy improved behavioral deficits in AD rodent models (McGeer and McGeer 2007). NSAIDs acts through inhibiting cyclooxygenase (COX) (Varvel et al. 2009), in particular, COX-1, as it is primarily expressed in microglia (Deardorff and Grossberg 2017), leading to blockade of microglial activation besides altered immune cells infiltration. COX-1 deficient mice exhibit reduced inflammation and neuronal injury levels in response to $A \beta$ (Choi and Bosetti 2009). NSAIDs can act as $\alpha$-, $\beta$-, and $\gamma$-secretase modulators, which help lessen amyloid deposition (Kukar and Golde 2008). Furthermore, they can directly interact with the $A \beta$ peptide inhibiting the formation of $A \beta$ oligomers and deposits (Kukar et al. 2008), which consequently attenuate microglial activation, the number of reactive astrocytes, and expression of proinflammatory molecules (Lim et al. 2000; Jantzen et al. 2002; Richardson et al. 2002; Yan et al. 2003; Heneka et al. 2005; Kotilinek et al. 2008). PPAR-gamma agonists as ibuprofen, indomethacin, and naproxen decrease promoter activity of the beta-site APP-cleaving enzyme 1 (BACE1) involved in APP processing as well (Sastre et al. 2006). Therefore, NSAIDs' beneficial effects have been attributed to their ability to reduce $A \beta$ generation, plaque size, and tau phosphorylation (Yoshiyama et al. 2007; Khoury and Luster 2008) with subsequent improvement in behavioral impairments (Lim et al. 2000, 2001; Sung et al. 2004; Kukar et al. 2007). 
NSAIDs can prevent the intellectual decline in older adults if started earlier, before age 65 (Hayden et al. 2007). Existing cognitive impairments limit their therapeutic usefulness (Martin et al. 2008). Ibuprofen and naproxen can block the early appearance of neuronal ectopic cell cycle events (CCEs), an early marker for risk of neurodegeneration (Busser et al. 1998; Yang et al. 2001, 2003), however, failed to reverse the current events in older mice (Varvel et al. 2009). Unexpectedly, NSAIDs can accelerate AD pathogenesis in advanced cases (Breitner et al. 2009) possibly, through inhibiting microglia-mediated clearance of $A \beta$ and the compensatory neurogenesis processes.

Naproxen, a common over-the-counter medicine, could help to prevent the progression of AD (Kim et al. 2011) through destabilizing preformed $A \beta$ fibrils, reducing their amounts (Agdeppa et al. 2003; Hirohata et al. 2005) besides antagonizing $A \beta$ aggregation (Cole and Frautschy 2010). Naproxen chronic administration blocked alterations in brain microglia and neuronal cell cycle events in young transgenic animals (Imbimbo et al. 2010). Long-term prophylactic use may reduce the risk of AD by $67 \%$ compared to placebo (Vlad et al. 2008; Imbimbo 2009; Imbimbo et al. 2010), though; it offers no therapeutic influence in preexisting AD cases (Gasparini et al. 2004; Imbimbo 2004). Our findings established the ability of naproxen to restore the architecture of pyramidal and Purkinje cells, although some of them were still shrunk, irregular, and deeply stained. Compared to the RIVA group, the RIVA+Napro proved to have an additive neuroprotective effect on the hippocampal pyramidal cells but could not provide extra benefit to the cerebellar Purkinje cells.

In our research, naproxen had a mitigating effect over $\mathrm{AlCl} 3$ anticholinergic action through decreased AChE activity. Hence, our findings agree with previous studies (Mostafa et al. 2016) that showed naproxen's ameliorative effect on AD-like behavioral performance through attenuating AChE activity. Our findings confirmed naproxen's ability to alleviate intellectual dysfunction caused by $\mathrm{AlCl} 3$ as evidenced by significantly augmenting the time exploring the novel objects, step-through latency, and spatial learning compatible with other studies' results (Jain et al. 2002). Chronic treatment with naproxen significantly improved colchicine-induced cognitive impairment (Kumar et al. 2006). Moreover, naproxen has potential neuroprotective properties against D-serine mediated excitotoxicity implicated in PD, Huntington's disease, multiple sclerosis, and AD (Armagan et al. 2012). Some reports, however, have argued against naproxen anti-Alzheimer role (Lyketsos et al. 2007; Martin et al. 2008; Imbimbo et al. 2010). When compared to the RIVA group, the RIVA+Napro group was unable to provide an additive cognitive improvement.

AD neuronal cell death can be attributed to apoptosis and DNA fragmentation (Chang et al. 2016). Disruption of mitochondrial homeostasis by high levels of reactive oxygen species (ROS) mediates the release of proapoptotic cytokines as cytochrome c (Tyagi et al. 2006; Liu et al. 2015) that bind to apoptotic protease activating factor 1 (Apaf-1) (Skulachev 1998; Ghribi et al. 2002; Al-olayan et al. 2015; Resseguie et al. 2015). This complex activates caspase-3, the major executioner in apoptosis (Lynch et al. 2000; Sjöbeck and Englund 2001; Chang et al. 2016), via proteolytic cleavage (Allan and Clarke 2009; Reubold and Eschenburg 2012) into two subunits which dimerize to form the active enzyme (Rotonda et al. 1996). A $\beta$ can induce neuronal apoptosis via activation of caspase-3 found colocalized within senile 
plaques of AD brains (Amelio et al. 2012; Cetin et al. 2013; Chang et al. 2016). Besides, studies have illustrated an apoptogenic role of AChE (Zhang and Greenberg 2012), which revealed the potential value of AChEls therapeutics in early AD (Toiber et al. 2008).

Our study showed that the protein level of the activated caspase-3 was significantly augmented in AlCl3intoxicated rats in the hippocampus and cerebellar tissues compared with the Cont group, which is in line with other research (Greilberger et al. 2008; Porsteinsson et al. 2008; Kumar and Kumar 2009; Al-olayan et al. 2015; Alawdi et al. 2017; Justin-Thenmozhi et al. 2018; Attia et al. 2020). AlCl3-induced activated caspase-3 overexpression was significantly attenuated by the concomitant treatment with rivastigmine. This is in line with other study reports that showed an ameliorating effect of rivastigmine over ADmediated caspase-3 overexpression (Elmegeed et al. 2015; Sachdeva and Chopra 2015). Similarly, activated caspase-3 overexpression caused by $\mathrm{AlCl} 3$ was significantly attenuated by concomitant naproxen administration. NSAIDs are competitive multi-caspase inhibitors, but their actions are more pronounced for caspases $-4,-5$, and -9 , with lower activity against caspase- 3 and -1 due to variations in the pocket recognition substrates (Smith et al. 2017). Caspase inhibition is recognized as a Coxindependent (Chan 2002) anti-inflammatory mechanism for NSAID drugs with a consequent decrease in cell death and proinflammatory cytokine production (Smith et al. 2017). When naproxen was given with rivastigmine, it had an additive antiapoptotic effect on the hippocampal CA1 region compared to rivastigmine alone. Still, according to our findings, it failed to have an additive antiapoptotic to the cerebellar Purkinje cells. On the contrary, other studies showed the ability of NSAIDs to induce apoptosis which lies behind their chemopreventive impact against cancer of the gastrointestinal tract (gastric or colorectal cancer) (Chan 2002; Jana 2008) lung, breast, and prostate cancers (Chan et al. 2005; Rothwell et al. 2010, 2012; Shebl et al. 2014; Seetha et al. 2020).

Recent studies have suggested the implication of neurogenesis in neurodegenerative disorders (Zhao et al. 2008; Lazarov et al. 2010; Mu and Gage 2011; Marxreiter et al. 2013). Deficits in adult neurogenesis may contribute to tau hyperphosphorylation in new neurons, compromised hippocampal circuitry, and cognitive impairments in AD (Hollands et al. 2017). Therefore, through pharmacological and genetic approaches, induction of neurogenesis can slow down disease progression (Cho et al. 2007). The neurogenesis process has been well acknowledged in two brain regions; the subventricular zone (SVZ) of the lateral ventricle and the subgranular zone (SGZ) of the hippocampus DG (Zhao et al. 2008).

Nevertheless, neurogenesis has still been specified in other regions of the adult mammalian brain as the neocortex, cerebellum, striatum, amygdala, and hypothalamus (Radad et al. 2017). The cerebellum encloses much of the adult brain's mature neurons (Wingate and Hatten 1999). It has a remarkable feature of being able to regenerate its cells by neurogenesis following damage (Andreotti et al. 2018). Strikingly, after its ablation by irradiation, the cerebellar external granular layer can be reconstituted (Altman et al. 1969) probably through cerebellar nestin-expressing progenitors, residing mostly in the Purkinje cell layer, that can differentiate into granule cell precursors (GCPs) and mature granule neurons (Wojcinski et al. 2017). Our study showed a significant reduction of nestin immunoreactivity in the granule cell layer of the Al group compared to the Cont group indicating impaired cellular proliferation 
that is consistent with other studies (Yu et al. 2018; Li et al. 2019; Ibrahim et al. 2021). However, concomitant administration of rivastigmine increased nestin immunoreactivity, presumably, due to compensation for cholinergic deficits (Tayebati et al. 2004). This was consistent with other research findings (Salem et al. 2014) that showed enhanced expression of the brain nestin gene by $65.2 \%$ through rivastigmine administration relative to the untreated AD population. Similarly, naproxen administrationinduced nestin protein overexpression may represent a therapeutic option to restore adult neurogenesis in $A D$ patients. Previous studies showed the potential effectiveness of one of the non-selective COX inhibitors, indomethacin, to restore adult neurogenesis in PD (Hain et al. 2018). When concurrently given with rivastigmine, naproxen exerted an additive effect in promoting neurogenesis relative to rivastigmineonly therapy. Therefore, it could possibly enhance rivastigmine anti-Alzheimer's activity.

\section{Conclusion}

$A D$ is an age-related neurodegenerative disorder manifested by cognitive disability commonly associated with neuropsychiatric disorders. The hippocampus and the cerebellum are the most commonly implicated in Al intoxication. They showed major neuronal degeneration with an increased amount of intensely stained shrunken cells within the pyramidal and Purkinje cell layers. Hippocampal astrogliosis with enhanced GFAP expression was detected as well. Naproxen has mitigated AlCl3-induced neurocognitive impairment as it upgraded memory performance, decreased step-through latency, and improved spatial learning and memory retrieval, most likely through decreased hippocampal AChE activity. Our study was the first to demonstrate the neuroprotective effect of naproxen in the $\mathrm{AlCl} 3$ Alzheimer's rat model when given concurrently with rivastigmine, the standard anti-Alzheimer drug, as it attenuated neuropathological changes through modifying neuronal turnover; apoptosis suppression (activated caspase-3 downregulation), and enhancement of neurogenesis (nestin upregulation). However, compared to rivastigmine-only therapy, naproxen concurrently administered with rivastigmine had no additional ameliorative effect on intellectual alterations in the AD rat model. Further research is still needed to determine whether naproxen given before clinical dementia or over a longer period will help delay $A D$ development when given in combination with rivastigmine.

\section{Declarations}

\section{Ethics approval:}

All the animal procedures were conducted with approval from the institutional Animal Care, and Use Committee of the Faculty of Medicine, Assiut University (IRB no:17100383) and could be given by request. They were carried out following the internationally accepted principles for laboratory animal use and care the US guidelines (NIH publication \#85-23, revised in 1985).

\section{Consent for publication:}


Not applicable.

\section{Availability of data and materials:}

Not applicable.

\section{Competing interests:}

All the authors declare that there are no competing financial interests concerning the work.

\section{Funding:}

We got fund from Assiut Medical School Grants Office, grant code 20171121002R1.

\section{Authors' contributions:}

The studies were conceived and planned by Raafat A. Abdel-Aal and Lobna A. Abdelzaher. The experiments were carried out by Lobna A. Abdelzaher, Reham G. Elsaady, and Ola A. Hussein. The data was analysed by Lobna A. Abdelzaher, Reham G. Elsaady, and Ola A. Hussein. Lobna A. Abdelzaher wrote the manuscript. The manuscript was revised by Raafat A. Abdel-Aal, Reham G. Elsaady, Lobna A. Abdelzaher, and Ola A. Hussein. The final manuscript was read and accepted by all contributors. All authors read and approved the final manuscript.

\section{Acknowledgements:}

The authors gratefully thank Assiut Medical School Grants Office for the financial support, grant code $20171121002 \mathrm{R} 1$.

\section{References}

1. Abdel-Aal RA, Assi AAA, Kostandy BB (2011) Memantine prevents aluminum-induced cognitive deficit in rats. Behav Brain Res 225:31-38

2. Abdi-Azar H, Maleki S (2014) Comparison of the anesthesia with thiopental sodium alone and their combination with Citrus aurantium L. (Rutaseae) essential oil in male rat. Bull Environ Pharmacol Life Sci 3:37-44

3. Abubakar MG, Taylor A, Ferns GAA (2004) Regional accumulation of aluminium in the rat brain is affected by dietary vitamin E. J Trace Elem Med Biol 18:53-59 
4. Agdeppa ED, Kepe V, Petri A et al (2003) In vitro detection of (S)-naproxen and ibuprofen binding to plaques in the Alzheimer's brain using the positron emission tomography molecular imaging probe 2(1-[6-[(2-[(18)F]fluoroethyl)(methyl)amino]-2-naphthyl]ethylidene)malononitrile. Neuroscience $117: 723-730$

5. Akhtar A, Bishnoi M, Sah SP (2020) Sodium orthovanadate improves learning and memory in intracerebroventricular-streptozotocin rat model of Alzheimer's disease through modulation of brain insulin resistance induced tau pathology. Brain Res Bull 164:83-97

6. Al-olayan EM, El-khadragy MF, Moneim AEA (2015) The protective properties of melatonin against aluminium-induced neuronal injury. Int J Exp Pathol 96:196-202

7. Alarcón R, Fuenzalida C, Santibáñez M, Bernhardi R von (2005) Expression of scavenger receptors in glial cells. Comparing the adhesion of astrocytes and microglia from neonatal rats to surface-bound beta-amyloid. J Biol Chem 280:30406-30415

8. Alawdi SH, El-Denshary ES, Safar MM et al (2017) Neuroprotective Effect of Nanodiamond in Alzheimer's Disease Rat Model: a Pivotal Role for Modulating NF-KB and STAT3 Signaling. Mol Neurobiol 54:1906-1918

9. Albright JE, Stojkovska I, Rahman AA et al (2016) Nestin-positive/SOX2-negative cells mediate adult neurogenesis of nigral dopaminergic neurons in mice. Neurosci Lett 615:50-54

10. Allan LA, Clarke PR (2009) Apoptosis and autophagy: Regulation of caspase-9 by phosphorylation. FEBS J 276:6063-6073

11. Allen JW, Eldadah BA, Huang $X$ et al (2001) Multiple caspases are involved in $\beta$-amyloid-induced neuronal apoptosis. J Neurosci Res 65:45-53

12. Alteri E, Guizzaro L (2018) Be open about drug failures to speed up research. Nature 563:317-319

13. Altman J, Anderson WJ, Wright KA (1969) Early effects of x-irradiation of the cerebellum in infant rats: decimation and reconstitution of the external granular layer. Exp Neurol 24:196-216

14. Altmann P, Cunningham J, Dhanesha U et al (1999) Disturbance of cerebral function in people exposed to drinking water contaminated with aluminium sulphate: retrospective study of the Camelford water incident. BMJ 319:807-811

15. Amelio MD, Sheng M, Cecconi F (2012) Caspase-3 in the central nervous system: beyond apoptosis. Trends Neurosci 35:700-709

16. Andreotti JP, Prazeres PHDM, Magno LAV et al (2018) Neurogenesis in the postnatal cerebellum after injury. Int J Dev Neurosci 67:33-36

17. Antunes M, Biala G (2012) The novel object recognition memory: Neurobiology, test procedure, and its modifications. Cogn Process 13:93-110

18. Ard MD, Cole GM, Wei J et al (1996) Scavenging of Alzheimer's Amyloid P-Protein by Microglia in Culture. J Neurosci Res 43:190-202

19. Armagan G, Kanit L, Yalcin A (2012) Effects of non-steroidal antiinflammatory drugs on D-serineinduced oxidative stress in vitro. Drug Chem Toxicol 35:393-398 
20. Arshavsky YI (2010) Why Alzheimer's disease starts with a memory impairment: neurophysiological insight. J Alzheimer's Dis 20:5-16

21. Attia H, Albuhayri S, Alaraidh S et al (2020) Biotin, coenzyme Q10, and their combination ameliorate aluminium chloride-induced Alzheimer's disease via attenuating neuroinflammation and improving brain insulin signaling. J Biochem Mol Toxicol 34:e22519

22. Ayasolla K, Khan M, Singh AK, Singh I (2004) Inflammatory mediator and $\beta$-amyloid (25-35)-induced ceramide generation and iNOS expression are inhibited by vitamin E. Free Radic Biol Med 37:325338

23. Bancroft JD, Gamble M (2008) Theory and Practice of Histological Techniques, 6th Edition. J Neuropathol Exp Neurol 67:633

24. Bazzari FH, Abdallah DM, El-abhar HS (2019) Chenodeoxycholic Acid Ameliorates AlCl3-Induced Alzheimer's Disease Neurotoxicity and Cognitive Deterioration via Enhanced Insulin Signaling in Rats. Molecules 24:1992

25. Beach TG, McGeer EG (1988) Lamina-specific arrangement of astrocytic gliosis and senile plaques in Alzheimer's disease visual cortex. Brain Res 463:357-361

26. Beach TG, Walker R, McGeer EG (1989) Patterns of gliosis in Alzheimer's disease and aging cerebrum. Glia 2:420-436

27. Benedikz E, Kloskowska E, Winblad B (2009) The rat as an animal model of Alzheimer's disease. J Cell Mol Med 13:1034-1042

28. Bhalla P, Dhawan DK (2009) Protective role of lithium in ameliorating the aluminium-induced oxidative stress and histological changes in rat brain. Cell Mol Neurobiol 29:513-521

29. Birks JS, Evans JG (2015) Rivastigmine for Alzheimer's disease. Cochrane Database Syst Rev 10:CD001191

30. Bondy SC (2016) Low levels of aluminum can lead to behavioral and morphological changes associated with Alzheimer's disease and age-related neurodegeneration. Neurotoxicology 52:222229

31. Brandenburg L-O, Konrad M, Wruck CJ et al (2010) Functional and physical interactions between formyl-peptide-receptors and scavenger receptor MARCO and their involvement in amyloid beta 1-42induced signal transduction in glial cells. J Neurochem 113:749-760

32. Breitner JC, Welsh KA, Helms MJ et al (1995) Delayed onset of Alzheimer's disease with nonsteroidal anti-inflammatory and histamine $\mathrm{H} 2$ blocking drugs. Neurobiol Aging 16:523-530

33. Breitner JCS, Haneuse SJPA, Walker R et al (2009) Risk of dementia and AD with prior exposure to NSAIDs in an elderly community-based cohort. Neurology 72:1899-1905

34. Busser J, Geldmacher DS, Herrup K (1998) Ectopic cell cycle proteins predict the sites of neuronal cell death in Alzheimer's disease brain. J Neurosci 18:2801-2807

35. Cai Z, Hussain MD, Yan LJ (2014) Microglia, neuroinflammation, and beta-amyloid protein in Alzheimer's disease. Int J Neurosci 124:307-321 
36. Caselli RJ, Beach TG, Yaari R, Reiman EM (2006) Alzheimer's disease a century later. J Clin Psychiatry 67:1784-1800

37. Castorina A, Tiralongo A, Giunta S et al (2010) Early effects of aluminum chloride on beta-secretase mRNA expression in a neuronal model of beta-amyloid toxicity. Cell Biol Toxicol 26:367-377

38. Cetin F, Yazihan N, Dincer S, Akbulut G (2013) The effect of intracerebroventricular injection of beta amyloid peptide (1-42) on caspase-3 activity, lipid peroxidation, nitric oxide and NOS expression in young adult and aged rat brain. Turk Neurosurg 23:144-150

39. Chan AT, Giovannucci EL, Meyerhardt JA et al (2005) Long-term use of aspirin and nonsteroidal antiinflammatory drugs and risk of colorectal cancer. JAMA 294:914-923

40. Chan TA (2002) Nonsteroidal anti-inflammatory drugs, apoptosis, and colon-cancer chemoprevention. Lancet Oncol 3:166-174

41. Chandra S, Jana M, Pahan K (2018) Aspirin Induces Lysosomal Biogenesis and Attenuates Amyloid Plaque Pathology in a Mouse Model of Alzheimer's Disease via PPARa. J Neurosci 38:6682-6699

42. Chang Y-J, Linh NH, Shih Y-H et al (2016) Alzheimer 's Amyloid- $\beta$ Sequesters Caspase-3 in vitro via its C-terminal Tail. ACS Chem Neurosci 7:1097-1106

43. Cho S-R, Benraiss A, Chmielnicki E et al (2007) Induction of neostriatal neurogenesis slows disease progression in a transgenic murine model of Huntington disease. J Clin Invest 117:2889-2902

44. Chogtu B, Arivazhahan A, Kunder SK et al (2018) Evaluation of Acute and Chronic Effects of DGalactose on Memory and Learning in Wistar Rats. Clin Psychopharmacol Neurosci 16:153-160

45. Choi S-H, Bosetti F (2009) Cyclooxygenase-1 null mice show reduced neuroinflammation in response to beta-amyloid. Aging 1:234-244

46. Citron M (2010) Alzheimer's disease: strategies for disease modification. Nat Rev Drug Discov 9:387-398

47. Cole GM, Frautschy SA (2010) Mechanisms of action of non-steroidal anti-inflammatory drugs for the prevention of Alzheimer's disease. CNS Neurol Disord Drug Targets 9:140-148

48. Colucci L, Bosco M, Fasanaro AM et al (2014) Alzheimer's disease costs: What we know and what we should take into account. J Alzheimer's Dis 42:1311-1324

49. Constam DB, Philipp J, Malipiero UV et al (1992) Differential expression of transforming growth factor-beta 1, -beta 2 , and -beta 3 by glioblastoma cells, astrocytes, and microglia. J Immunol 148:1404-1410

50. Côté S, Carmichael P-H, Verreault R et al (2012) Nonsteroidal anti-inflammatory drug use and the risk of cognitive impairment and Alzheimer's disease. Alzheimers Dement 8:219-226

51. Crapper DR, Krishnan SS, Dalton AJ (1973) Brain aluminum distribution in Alzheimer's disease and experimental neurofibrillary degeneration. Science 180:511-513

52. Deardorff WJ, Grossberg GT (2017) Targeting neuroinflammation in Alzheimer 's disease: evidence for NSAIDs and novel therapeutics. Expert Rev Neurother 17:17-32 
53. Deiana S, Harrington CR, Wischik CM, Riedel G (2009) Methylthioninium chloride reverses cognitive deficits induced by scopolamine: comparison with rivastigmine. Psychopharmacol 202:53-65

54. Dingledine R, Borges K, Bowie D, Traynelis SF (1999) The Glutamate Receptor lon Channels. Pharmacol Rev 51:7-61

55. Elmegeed GA, Ahmed HH, Hashash MA et al (2015) Synthesis of novel steroidal curcumin derivatives as anti-Alzheimer's disease candidates: Evidences-based on in vivo study. Steroids 101:78-89

56. Erazi H, Sansar W, Ahboucha S, Gamrani H (2010) Aluminum affects glial system and behavior of rats. C R Biol 333:23-27

57. Evrard PA, Ragusi C, Boschi G et al (1998) Simultaneous microdialysis in brain and blood of the mouse: extracellular and intracellular brain colchicine disposition. Brain Res 786:122-127

58. Exley C, Esiri MM (2006) Severe cerebral congophilic angiopathy coincident with increased brain aluminium in a resident of Camelford, Cornwall, UK. J Neurol Neurosurg Psychiatry 77:877-879

59. Feng Y, Li L, Sun X-H (2011) Monocytes and Alzheimer's disease. Neurosci Bull 27:115-122

60. Ferreira-Vieira TH, Guimaraes IM, Silva FR, Ribeiro FM (2016) Alzheimer's disease: Targeting the Cholinergic System. Curr Neuropharmacol 14:101-115

61. Fischer P, Zehetmayer S, Jungwirth S et al (2008) Risk factors for Alzheimer dementia in a community-based birth cohort at the age of 75 years. Dement Geriatr Cogn Disord 25:501-507

62. Fishman EB, Siek GC, MacCallum RD et al (1986) Distribution of the molecular forms of acetylcholinesterase in human brain: alterations in dementia of the Alzheimer type. Ann Neurol 19:246-252

63. Furman JL, Sama DM, Gant JC et al (2012) Targeting astrocytes Ameliorates neurologic changes in a mouse model of Alzheimer's disease. J Neurosci 32:16129-16140

64. Garção P, Oliveira CR, Agostinho P (2006) Comparative study of microglia activation induced by amyloid-beta and prion peptides: Role in neurodegeneration. J Neurosci Res 84:182-193

65. Gasparini L, Ongini E, Wenk G (2004) Non-steroidal anti-inflammatory drugs (NSAIDs) in Alzheimer's disease: old and new mechanisms of action. J Neurochem 91:521-536

66. Gauthier E, Fortier I, Courchesne F et al (2000) Aluminum Forms in Drinking Water and Risk of Alzheimer's Disease. Environ Res 84:234-246

67. Ghosal K, Stathopoulos A, Pimplikar SW (2010) APP Intracellular Domain Impairs Adult Neurogenesis in Transgenic Mice by Inducing Neuroinflammation. PLoS One 5:e11866

68. Ghribi O, Herman MM, Savory J (2002) The endoplasmic reticulum is the main site for caspase-3 activation following aluminum-induced neurotoxicity in rabbit hippocampus. Neurosci Lett 324:217221

69. Giacobini E, Spiegel R, Enz A et al (2002) Inhibition of acetyl- and butyryl-cholinesterase in the cerebrospinal fluid of patients with Alzheimer's disease by rivastigmine: correlation with cognitive benefit. J Neural Transm 109:1053-1065 
70. Giorgianni C, Faranda M, Brecciaroli R et al (2003) Cognitive disorders among welders exposed to aluminum. G Ital Med Lav Ergon 25:102-103

71. Goldman SA (2006) Neural Progenitor Cells of the Adult Human Brain. Neural Dev Stem Cells 267297

72. Gothwal A, Singh H, Jain SK et al (2019) Behavioral and Biochemical Implications of Dendrimeric Rivastigmine in Memory-Deficit and Alzheimer's Induced Rodents. ACS Chem Neurosci 10:37893795

73. Grathwohl SA, Kälin RE, Bolmont T et al (2009) Formation and maintenance of Alzheimer's disease $\beta$-amyloid plaques in the absence of microglia. Nat Neurosci 12:1361-1363

74. Greig NH, Utsuki T, Yu Q et al (2001) A new therapeutic target in Alzheimer's disease treatment: attention to butyrylcholinesterase. Curr Med Res Opin 17:159-165

75. Greilberger J, Koidl C, Greilberger M et al (2008) Malondialdehyde, carbonyl proteins and albumindisulphide as useful oxidative markers in mild cognitive impairment and Alzheimer's disease. Free Radic Res 42:633-638

76. Guo-ross SX, Yang EY, Walsh TJ, Bondy SC (1999) Decrease of Glial Fibrillary Acidic Protein in Rat Frontal Cortex Following Aluminum Treatment. J Neurochem 73:1609-1614

77. Guo Q, Fu W, Xie J et al (1998) Par-4 is a mediator of neuronal degeneration associated with the pathogenesis of Alzheimer disease. Nat Med 4:957-962

78. Hain EG, Sparenberg M, Rasi J et al (2018) Indomethacin promotes survival of new neurons in the adult murine hippocampus accompanied by anti-inflammatory effects following MPTP-induced dopamine depletion. J Neuroinflammation 15:162

79. Hammond P, Brimijoin S (1988) Acetylcholinesterase in Huntington's and Alzheimer's diseases: simultaneous enzyme assay and immunoassay of multiple brain regions. J Neurochem 50:11111116

80. Harada J, Sugimoto M (1999) Activation of caspase-3 in $\beta$-amyloid-induced apoptosis of cultured rat cortical neurons. Brain Res 842:311-323

81. Hayden KM, Zandi PP, Khachaturian AS et al (2007) Does NSAID use modify cognitive trajectories in the elderly? The Cache County study. Neurology 69:275-282

82. Heneka MT, Carson MJ, Khoury J, El et al (2015) Neuroinflammation in Alzheimer's disease. Lancet Neurol 14:388-405

83. Heneka MT, Sastre M, Dumitrescu-Ozimek L et al (2005) Acute treatment with the PPARgamma agonist pioglitazone and ibuprofen reduces glial inflammation and Abeta1-42 levels in APPV717I transgenic mice. Brain 128:1442-1453

84. Hensley K (2010) Neuroinflammation in Alzheimer's Disease: Mechanisms, Pathologic Consequences, and Potential for Therapeutic Manipulation. J Alzheimer's Dis 21:1-14

85. Herrera VL, Makrides SC, Xie HX et al (1999) Spontaneous combined hyperlipidemia, coronary heart disease and decreased survival in Dahl salt-sensitive hypertensive rats transgenic for human 
cholesteryl ester transfer protein. Nat Med 5:1383-1389

86. Hickman SE, Allison EK, Khoury J El (2008) Microglial Dysfunction and Defective $\beta$-Amyloid Clearance Pathways in Aging Alzheimer's Disease Mice. J Neurosci 28:8354-8360

87. Hirohata M, Ono K, Naiki H, Yamada M (2005) Non-steroidal anti-inflammatory drugs have antiamyloidogenic effects for Alzheimer's beta-amyloid fibrils in vitro. Neuropharmacology 49:10881099

88. Hollands C, Bartolotti N, Lazarov 0 (2016) Alzheimer's Disease and Hippocampal Adult Neurogenesis; Exploring Shared Mechanisms. Front Neurosci 10:178

89. Hollands C, Tobin MK, Hsu M et al (2017) Depletion of adult neurogenesis exacerbates cognitive deficits in Alzheimer' s disease by compromising hippocampal inhibition. Mol Neurodegener 12:64

90. Hörsten S von, Schmitt I, Nguyen HP et al (2003) Transgenic rat model of Huntington's disease. Hum Mol Genet 12:617-624

91. Hou L, Liu Y, Wang X et al (2011) The effects of amyloid- $\beta 42$ oligomer on the proliferation and activation of astrocytes in vitro. Vitr Cell Dev Biol - Anim 47:573-580

92. Hu J, Akama KT, Krafft GA et al (1998) Amyloid- $\beta$ peptide activates cultured astrocytes: Morphological alterations, cytokine induction and nitric oxide release. Brain Res 785:195-206

93. Ibrahim MA, Haleem M, AbdelWahab SA, Abdel-Aziz AM (2021) Sildenafil ameliorates Alzheimer disease via the modulation of vascular endothelial growth factor and vascular cell adhesion molecule-1 in rats. Hum Exp Toxicol 40:596-607

94. Ikram MF, Farhat SM, Mahboob A et al (2020) Expression of DnMTs and MBDs in AlCl 3-Induced Neurotoxicity Mouse Model. Biol Trace Elem Res 199:3433-3444

95. Imbimbo BP (2009) An update on the efficacy of non-steroidal anti-inflammatory drugs in Alzheimer's disease. Expert Opin Investig Drugs 18:1147-1168

96. Imbimbo BP (2004) The potential role of non-steroidal anti-inflammatory drugs in treating Alzheimer's disease. Expert Opin Investig Drugs 13:1469-1481

97. Imbimbo BP, Solfrizzi V, Panza F (2010) Are NSAIDs useful to treat Alzheimer's disease or mild cognitive impairment? Front Aging Neurosci 2:PMC2912027

98. Iqbal K, Grundke-Iqbal I (2008) Alzheimer neurofibrillary degeneration: Significance, etiopathogenesis, therapeutics and prevention: Alzheimer Review Series. J Cell Mol Med 12:38-55

99. Ismail MF, Elmeshad AN, Salem NA-H (2013) Potential therapeutic effect of nanobased formulation of rivastigmine on rat model of Alzheimer's disease. Int J Nanomedicine 8:393-406

100. Jain NK, Patil CS, Kulkarni SK, Singh A (2002) Modulatory role of cyclooxygenase inhibitors in agingand scopolamine or lipopolysaccharide-induced cognitive dysfunction in mice. Behav Brain Res 133:369-376

101. Jana NR (2008) NSAIDs and apoptosis. Cell Mol Life Sci 65:1295-1301

102. Jangra A, Kasbe P, Pandey SN et al (2015) Hesperidin and Silibinin Ameliorate Aluminum-Induced Neurotoxicity: Modulation of Antioxidants and Inflammatory Cytokines Level in Mice Hippocampus. 
Biol Trace Elem Res 168:462-471

103. Jantzen PT, Connor KE, DiCarlo G et al (2002) Microglial activation and beta-amyloid deposit reduction caused by a nitric oxide-releasing nonsteroidal anti-inflammatory drug in amyloid precursor protein plus presenilin-1 transgenic mice. J Neurosci 22:2246-2254

104. Jenkinson ML, Bliss MR, Brain AT, Scott DL (1989) Rheumatold arthritis and senile dementia of the alzhelmer's type. Br J Rheumatol 28:86-88

105. Johnstone M, Gearing AJ, Miller KM (1999) A central role for astrocytes in the inflammatory response to $\beta$-amyloid; chemokines, cytokines and reactive oxygen species are produced. J Neuroimmunol 93:182-193

106. Junior AFS, Aguiar MSS, Junior OSC et al (2013) Hippocampal neuronal loss, decreased GFAP immunoreactivity and cognitive impairment following experimental intoxication of rats with aluminum citrate. Brain Res 1491:23-33

107. Justin-Thenmozhi A, Bharathi MD, Kiruthika R et al (2018) Attenuation of Aluminum Chloride-Induced Neuroinflammation and Caspase Activation Through the AKT / GSK-3 $\beta$ Pathway by Hesperidin in Wistar Rats. Neurotox Res 34:463-476

108. Kaizer RR, Corrêa MC, Gris LRS et al (2008) Effect of long-term exposure to aluminum on the acetylcholinesterase activity in the central nervous system and erythrocytes. Neurochem Res 33:2294-2301

109. Kamphuis W, Mamber C, Moeton M et al (2012) GFAP isoforms in adult mouse brain with a focus on neurogenic astrocytes and reactive astrogliosis in mouse models of Alzheimer disease. PLoS One 7:e42823

110. Kandiah N, Pai M, Looi l et al (2017) Rivastigmine: the advantages of dual inhibition of acetylcholinesterase and butyrylcholinesterase and its role in subcortical vascular dementia and Parkinson's disease dementia. Clin Interv Aging 12:697-707

111. Kashon ML, Ross GW, O’Callaghan JP et al (2004) Associations of cortical astrogliosis with cognitive performance and dementia status. J Alzheimer's Dis 6:595-604

112. Kaur A, Gill KD (2006) Possible peripheral markers for chronic aluminium toxicity in Wistar rats. Toxicol Ind Heal 22:39-46

113. Kawahara M, Kato-Negishi M (2011) Link between Aluminum and the Pathogenesis of Alzheimer's Disease: The Integration of the Aluminum and Amyloid Cascade Hypotheses. Int J Alzheimers Dis 2011:276393

114. Khoury J, El, Hickman SE, Thomas CA et al (1996) Scavenger receptor-mediated adhesion of microglia to $\beta$-amyloid fibrils. Nature 382:716-719

115. Khoury J, El, Luster AD (2008) Mechanisms of microglia accumulation in Alzheimer's disease: therapeutic implications. Trends Pharmacol Sci 29:626-632

116. Kim S, Chang WE, Kumar R, Klimov DK (2011) Naproxen Interferes with the Assembly of A $\beta$ Oligomers Implicated in Alzheimer's Disease. Biophys J 100:2024-2032 
117. Kim TW, Pettingell WH, Jung YK et al (1997) Alternative cleavage of Alzheimer-associated presenilins during apoptosis by a caspase-3 family protease. Science 277:373-376

118. Kinney JW, Bemiller SM, Murtishaw AS et al (2018) Inflammation as a central mechanism in Alzheimer's disease. Alzheimer's Dement Transl Res Clin Interv 4:575-590

119. Kotilinek LA, Westerman MA, Wang Q et al (2008) Cyclooxygenase-2 inhibition improves amyloid- $\beta$ mediated suppression of memory and synaptic plasticity. Brain 131:651-664

120. Kukar T, Golde TE (2008) Possible mechanisms of action of NSAIDs and related compounds that modulate gamma-secretase cleavage. Curr Top Med Chem 8:47-53

121. Kukar T, Prescott S, Eriksen JL et al (2007) Chronic administration of R-flurbiprofen attenuates learning impairments in transgenic amyloid precursor protein mice. BMC Neurosci 8:54

122. Kukar TL, Ladd TB, Bann MA et al (2008) Substrate-targeting gamma-secretase modulators. Nature 453:925-929

123. Kumar A, Seghal N, Padi SV, Naidu PS (2006) Differential effects of cyclooxygenase inhibitors on intracerebroventricular colchicine-induced dysfunction and oxidative stress in rats. Eur J Pharmacol 551:58-66

124. Kumar P, Kumar A (2009) Protective effect of rivastigmine against 3-nitropropionic acid-induced Huntington's disease like symptoms: Possible behavioural, biochemical and cellular alterations. Eur J Pharmacol 615:91-101

125. Kumar S (1998) Biphasic effect of aluminium on cholinergic enzyme of rat brain. Neurosci Lett 248:121-123

126. Kunjathoor VV, Tseng AA, Medeiros LA et al (2004) beta-Amyloid promotes accumulation of lipid peroxides by inhibiting CD36-mediated clearance of oxidized lipoproteins. J Neuroinflammation 1:23

127. LaFerla FM, Troncoso JC, Strickland DK et al (1997) Neuronal cell death in Alzheimer's disease correlates with apoE uptake and intracellular $A \beta$ stabilization. J Clin Invest 100:310-320

128. Lakshmi BVS, Sudhakar M, Prakash KS (2015) Protective Effect of Selenium Against Aluminum Chloride-Induced Alzheimer's Disease: Behavioral and Biochemical Alterations in Rats. Biol Trace Elem Res 165:67-74

129. Landi F, Cesari M, Onder G et al (2003) Non-steroidal anti-inflammatory drug (NSAID) use and Alzheimer disease in community-dwelling elderly patients. Am J Geriatr Psychiatry 11:179-185

130. Lazarov O, Mattson MP, Peterson DA et al (2010) When neurogenesis encounters aging and disease. Trends Neurosci 33:569-579

131. Leifer BP (2003) Early diagnosis of Alzheimer's disease: Clinical and economic benefits. J Am Geriatr Soc 51:S281-S288

132. Li J, Han Y, Li M, Nie C (2019) Curcumin Promotes Proliferation of Adult Neural Stem Cells and the Birth of Neurons in Alzheimer's Disease Mice via Notch Signaling Pathway. Cell Reprogram 21:152161 
133. Li X-B, Zheng H, Zhang Z-R et al (2009) Glia activation induced by peripheral administration of aluminum oxide nanoparticles in rat brains. Nanomedicine 5:473-479

134. Li X, Bao X, Wang R (2016) Experimental models of Alzheimer's disease for deciphering the pathogenesis and therapeutic screening (Review). Int J Mol Med 37:271-283

135. Liddelow SA, Guttenplan KA, Clarke LE et al (2017) Neurotoxic reactive astrocytes are induced by activated microglia. Nature 541:481-487

136. Lim GP, Yang F, Chu T et al (2000) Ibuprofen suppresses plaque pathology and inflammation in a mouse model for Alzheimer's disease. J Neurosci 20:5709-5714

137. Lim GP, Yang F, Chu T et al (2001) Ibuprofen effects on Alzheimer pathology and open field activity in APPsw transgenic mice. Neurobiol Aging 22:983-991

138. Liu CC, Zhao N, Yamaguchi Y et al (2016) Neuronal heparan sulfates promote amyloid pathology by modulating brain amyloid- $\beta$ clearance and aggregation in Alzheimer's disease. Sci Transl Med 8:332ra44

139. Liu H, Wang L, Su W, Xie XQ (2014) Advances in recent patent and clinical trial drug development for Alzheimer's disease. Pharm Pat Anal 3:429-447

140. Liu X, Wang J, Lu C et al (2015) The role of lysosomes in BDE 47-mediated activation of mitochondrial apoptotic pathway in HepG2 cells. Chemosphere 124:10-21

141. Loeffler DA (2004) Using animal models to determine the significance of complement activation in Alzheimer's disease. J Neuroinflammation 1:18

142. Lyketsos CG, Breitner JCS, Green RC et al (2007) Naproxen and celecoxib do not prevent AD in early results from a randomized controlled trial. Neurology 68:1800-1808

143. Lynch T, Cherny RA, Bush Al (2000) Oxidative processes in Alzheimer's disease: The role of Aß-metal interactions. Exp Gerontol 35:445-451

144. Mahdy K, Shaker O, Wafay H et al (2012) Effect of some medicinal plant extracts on the oxidative stress status in Alzheimer's disease induced in rats. Eur Rev Med Pharmacol Sci 16:31-42

145. Majumdar A, Capetillo-Zarate E, Cruz D et al (2011) Degradation of Alzheimer's amyloid fibrils by microglia requires delivery of ClC-7 to lysosomes. Mol Biol Cell 22:1664-1676

146. Martin BK, Szekely C, Brandt J et al (2008) Cognitive Function Over Time in the Alzheimer's Disease Antiinflammatory Prevention Trial (ADAPT): Results of a Randomized, Controlled Trial of Naproxen and Celecoxib. Arch Neurol 65:896-905

147. Marxreiter F, Regensburger M, Winkler J (2013) Adult neurogenesis in Parkinson's disease. Cell Mol Life Sci 70:459-473

148. Matsuda T, Hisatsune T (2017) Cholinergic Modification of Neurogenesis and Gliosis Improves the Memory of AßPPswe/PSEN1dE9 Alzheimer's Disease Model Mice Fed a High-Fat Diet. J Alzheimers Dis $56: 1-23$

149. Mawuenyega KG, Sigurdson W, Ovod V et al (2010) Decreased clearance of CNS $\beta$-amyloid in Alzheimer's disease. Science 330:1774 
150. McGeer PL, McGeer EG (1995) The inflammatory response system of brain: implications for therapy of Alzheimer and other neurodegenerative diseases. Brain Res Rev 21:195-218

151. McGeer PL, McGeer EG (2007) NSAIDs and Alzheimer disease: epidemiological, animal model and clinical studies. Neurobiol Aging 28:639-647

152. McGeer PL, Schulzer M, McGeer EG (1996) Arthritis and anti-inflammatory agents as possible protective factors for Alzheimer's disease: a review of 17 epidemiologic studies. Neurology 47:425432

153. McLachlan DR, Bergeron C, Smith JE et al (1996) Risk for neuropathologically confirmed Alzheimer's disease and residual aluminum in municipal drinking water employing weighted residential histories. Neurology 46:401-405

154. Mehrabadi S, Motevaseli E, Sadr SS, Moradbeygi K (2020) Hypoxic-conditioned medium from adipose tissue mesenchymal stem cells improved neuroinflammation through alternation of toll like receptor (TLR) 2 and TLR4 expression in model of Alzheimer's disease rats. Behav Brain Res 379:112362

155. Misawa T, Shigeta S (1992) Behavioral effects of repeated aluminum administration in the rat. Tokai J Exp Clin Med 17:155-159

156. Mohamed LA, Keller JN, Kaddoumi A (2016) Role of P-glycoprotein in mediating rivastigmine effect on amyloid- $\beta$ brain load and related pathology in Alzheimer's disease mouse model. Biochim Biophys Acta 1862:778-787

157. Moreno-Jiménez EP, Flor-García M, Terreros-Roncal J et al (2019) Adult hippocampal neurogenesis is abundant in neurologically healthy subjects and drops sharply in patients with Alzheimer's disease. Nat Med 25:554-560

158. Mostafa DK, El Azhary NM, Nasra RA (2016) The hydrogen sulfide releasing compounds ATB-346 and diallyl trisulfide attenuate streptozotocin-induced cognitive impairment, neuroinflammation, and oxidative stress in rats: Involvement of asymmetric dimethylarginine. Can J Physiol Pharmacol 94:699-708

159. Mrak RE, Sheng JG, Griffin WS (1996) Correlation of astrocytic S100 beta expression with dystrophic neurites in amyloid plaques of Alzheimer's disease. J Neuropathol Exp Neurol 55:273-279

160. Mu Y, Gage FH (2011) Adult hippocampal neurogenesis and its role in Alzheimer's disease. Mol Neurodegener 6:85

161. Mucke L, Selkoe DJ (2012) Neurotoxicity of amyloid $\beta$-protein: Synaptic and network dysfunction. Cold Spring Harb Perspect Med 2:a006338

162. Mustafa HN (2020) Neuro-amelioration of cinnamaldehyde in aluminum-induced Alzheimer's disease rat model. J Histotechnol 43:11-20

163. Nagele RG, D'Andrea MR, Lee $\mathrm{H}$ et al (2003) Astrocytes accumulate A beta 42 and give rise to astrocytic amyloid plaques in Alzheimer disease brains. Brain Res 971:197-209

164. Nampoothiri M, John J, Kumar $\mathrm{N}$ et al (2015) Modulatory Role of Simvastatin against Aluminium Chloride-Induced Behavioural and Biochemical Changes in Rats. Behav Neurol 2015:210169 
165. Nampoothiri M, Kumar N, Ramalingayya GV et al (2017) Effect of insulin on spatial memory in aluminum chloride-induced dementia in rats. Neuroreport 28:540-544

166. Nazem A, Sankowski R, Bacher M, Al-Abed Y (2015) Rodent models of neuroinflammation for Alzheimer's disease. J Neuroinflammation 12:74

167. Nhan HS, Chiang K, Koo EH (2015) The multifaceted nature of amyloid precursor protein and its proteolytic fragments: friends and foes. Acta Neuropathol 129:1-19

168. Olabarria M, Noristani HN, Verkhratsky A, Rodríguez JJ (2010) Concomitant astroglial atrophy and astrogliosis in a triple transgenic animal model of Alzheimer's disease. Glia 58:831-838

169. Onor ML, Trevisiol M, Aguglia E (2007) Rivastigmine in the treatment of Alzheimer's disease: an update. Clin Interv Aging 2:17-32

170. Paresce DM, Ghosh RN, Maxfield FR (1996) Microglial cells internalize aggregates of the Alzheimer's disease amyloid beta-protein via a scavenger receptor. Neuron 17:553-565

171. Peder Flaten T (2001) Aluminium as a risk factor in Alzheimer's disease, with emphasis on drinking water. Brain Res Bull 55:187-196

172. Perlmutter LS, Scott SA, Barrón E, Chui HC (1992) MHC class II-positive microglia in human brain: Association with alzheimer lesions. J Neurosci Res 33:549-558

173. Platt B, Fiddler G, Riedel G, Henderson Z (2001) Aluminium toxicity in the rat brain: histochemical and immunocytochemical evidence. Brain Res Bull 55:257-267

174. Polizzi S, Pira E, Ferrara M et al (2002) Neurotoxic effects of aluminium among foundry workers and Alzheimer's disease. Neurotoxicology 23:761-774

175. Porsteinsson AP, Grossberg GT, Mintzer J, Olin JT (2008) Memantine treatment in patients with mild to moderate Alzheimer's disease already receiving a cholinesterase inhibitor: a randomized, doubleblind, placebo-controlled trial. Curr Alzheimer Res 5:83-89

176. Rabe A, Lee MH, Shek J, M.Wisniewski H (1982) Learning deficit in immature rabbits with aluminuminduced neurofibrillary changes. Exp Neurol 76:441-446

177. Radad K, Moldzio R, Al-Shraim M et al (2017) Recent Advances on the Role of Neurogenesis in the Adult Brain: Therapeutic Potential in Parkinson's and Alzheimer's Diseases. CNS Neurol Disord Drug Targets 16:740-748

178. Ray B, Lahiri DK (2009) Neuroinflammation in Alzheimer's disease: different molecular targets and potential therapeutic agents including curcumin. Curr Opin Pharmacol 9:434-444

179. Reddy AP, Ravichandran J, Carkaci-Salli N (2020) Neural regeneration therapies for Alzheimer's and Parkinson's disease-related disorders. Biochim Biophys Acta - Mol Basis Dis 1866:165506

180. Reid W, Sadowska M, Denaro F et al (2001) An HIV-1 transgenic rat that develops HIV-related pathology and immunologic dysfunction. Proc Natl Acad Sci U S A 98:9271-9276

181. Resseguie EA, Staversky RJ, Brookes PS, O’Reilly MA (2015) Hyperoxia activates ATM independent from mitochondrial ROS and dysfunction. Redox Biol 5:176-185 
182. Reubold TF, Eschenburg S (2012) A molecular view on signal transduction by the apoptosome. Cell Signal 24:1420-1425

183. Richardson RL, Kim E-M, Shephard RA et al (2002) Behavioural and histopathological analyses of ibuprofen treatment on the effect of aggregated Abeta(1-42) injections in the rat. Brain Res 954:110

184. Rifat SL, Eastwood MR, McLachlan DR, Corey PN (1990) Effect of exposure of miners to aluminium powder. Lancet 336:1162-1165

185. Rodríguez-Puertas R, Pazos A, Zarranz JJ, Pascual J (1994) Selective cortical decrease of highaffinity choline uptake carrier in Alzheimer's disease: an autoradiographic study using $3 \mathrm{H}-$ hemicholinium-3. J Neural Transm Park Dis Dement Sect 8:161-169

186. Rodríguez JJ, Olabarria M, Chvatal A, Verkhratsky A (2009) Astroglia in dementia and Alzheimer's disease. Cell Death Differ 16:378-385

187. Roskams AJ, Connor JR (1990) Aluminum access to the brain: a role for transferrin and its receptor. Proc Natl Acad Sci U S A 87:9024-9027

188. Rothwell PM, Price JF, Fowkes FGR et al (2012) Short-term effects of daily aspirin on cancer incidence, mortality, and non-vascular death: analysis of the time course of risks and benefits in 51 randomised controlled trials. Lancet 379:1602-1612

189. Rothwell PM, Wilson M, Elwin C-E et al (2010) Long-term effect of aspirin on colorectal cancer incidence and mortality: 20-year follow-up of five randomised trials. Lancet 376:1741-1750

190. Rotonda J, Nicholson DW, Fazil KM et al (1996) The three-dimensional structure of apopain/ CPP32, a key mediator of apoptosis. Nat Struct Biol 3:619-625

191. Sachdeva AK, Chopra K (2015) Lycopene abrogates $A \beta(1-42)$-mediated neuroinflammatory cascade in an experimental model of Alzheimer's disease. J Nutr Biochem 26:736-744

192. Said MM, Rabo MMA (2017) Neuroprotective effects of eugenol against aluminium induced toxicity in the rat brain. Arh Hig Rada Toksikol 68:27-37

193. Sakamoto T, Ogasawara Y, Ishii K et al (2004) Accumulation of aluminum in ferritin isolated from rat brain. Neurosci Lett 366:264-267

194. Salem AM, Ahmed HH, Atta HM et al (2014) Potential of bone marrow mesenchymal stem cells in management of Alzheimer's disease in female rats. Cell Biol Int 38:1367-1383

195. Sanz-Blasco S, Valero RA, Rodríguez-Crespo I et al (2008) Mitochondrial Ca 2 + overload underlies A $\beta$ oligomers neurotoxicity providing an unexpected mechanism of neuroprotection by NSAIDs. PLoS One 3:e2718

196. Sastre M, Dewachter I, Rossner S et al (2006) Nonsteroidal anti-inflammatory drugs repress $\beta$ secretase gene promoter activity by the activation of PPARY. Proc Natl Acad Sci U S A 103:443-448

197. Schwab C, McGeer PL (2008) Inflammatory aspects of Alzheimer disease and other neurodegenerative disorders. J Alzheimer's Dis 13:359-369 
198. Scuderi C, Stecca C, Valenza M et al (2014) Palmitoylethanolamide controls reactive gliosis and exerts neuroprotective functions in a rat model of Alzheimer's disease. Cell Death Dis 5:e1419

199. Seetha A, Devaraj H, Sudhandiran G (2020) Indomethacin and juglone inhibit inflammatory molecules to induce apoptosis in colon cancer cells. J Biochem Mol Toxicol 34:e22433

200. Shebl FM, Hsing AW, Park Y et al (2014) Non-steroidal anti-inflammatory drugs use is associated with reduced risk of inflammation-associated cancers: NIH-AARP study. PLoS One 9:e114633

201. Sil S, Goswami AR, Dutta G, Ghosh T (2014) Effects of Naproxen on Immune Responses in a Colchicine-Induced Rat Model of Alzheimer's Disease. Neuroimmunomodulation 21:304-321

202. Singh-Bains MK, Linke V, Austria MDR et al (2019) Altered microglia and neurovasculature in the Alzheimer's disease cerebellum. Neurobiol Dis 132:104589

203. Sjöbeck M, Englund E (2001) Alzheimer's disease and the cerebellum: A morphologic study on neuronal and glial changes. Dement Geriatr Cogn Disord 12:211-218

204. Skulachev VP (1998) Cytochrome $\mathrm{c}$ in the apoptotic and antioxidant cascades. FEBS Lett 423:275280

205. Slanina P, Falkeborn Y, Frech W, Cedergren A (1984) Aluminium concentrations in the brain and bone of rats fed citric acid, aluminium citrate or aluminium hydroxide. Food Chem Toxicol 22:391-397

206. Smith CE, Soti S, Jones TA et al (2017) NSAIDs are Caspase Inhibitors. Cell Chem Biol 24:281-292

207. Spangenberg EE, Green KN (2017) Inflammation in Alzheimer's disease: Lessons learned from microglia-depletion models. Brain Behav Immun 61:1-11

208. Stewart WF, Kawas C, Corrada M, Metter EJ (1997) Risk of Alzheimer's disease and duration of NSAID use. Neurology 48:626-632

209. Sun Z-K, Yang HQ, Chen S, Di (2013) Traditional Chinese medicine: A promising candidate for the treatment of Alzheimer's disease. Transl Neurodegener 2:6

210. Sung PS, Lin PY, Liu CH et al (2020) Neuroinflammation and neurogenesis in alzheimer's disease and potential therapeutic approaches. Int J Mol Sci 21:701

211. Sung S, Yang H, Uryu K et al (2004) Modulation of nuclear factor-kappa B activity by indomethacin influences $A$ beta levels but not $A$ beta precursor protein metabolism in a model of Alzheimer's disease. Am J Pathol 165:2197-2206

212. Szekely CA, Breitner JCS, Fitzpatrick AL et al (2008) NSAID Use and Dementia Risk in the Cardiovascular Health Study: Role of APOE and NSAID Type. Neurology 70:17-24

213. Tayebati SK, Tullio MA, Di, Amenta F (2004) Effect of treatment with the cholinesterase inhibitor rivastigmine on vesicular acetylcholine transporter and choline acetyltransferase in rat brain. Clin Exp Hypertens 26:363-373

214. Teng E, Kepe V, Frautschy SA et al (2011) [ F-18 ] FDDNP microPET imaging correlates with brain A $\beta$ burden in a transgenic rat model of Alzheimer disease: Effects of aging, in vivo blockade, and anti-A $\beta$ antibody treatment. Neurobiol Dis 43:565-575 
215. Toiber D, Berson A, Greenberg D et al (2008) N-Acetylcholinesterase-Induced Apoptosis in Alzheimer's Disease. PLoS One 3:e3108

216. Townsend KP, Praticò D (2005) Novel therapeutic opportunities for Alzheimer's disease: focus on nonsteroidal anti-inflammatory drugs. FASEB J 19:1592-1601

217. Tyagi N, Ovechkin AV, Lominadze D et al (2006) Mitochondrial mechanism of microvascular endothelial cells apoptosis in hyperhomocysteinemia. J Cell Biochem 98:1150-1162

218. Varvel NH, Bhaskar K, Kounnas MZ et al (2009) NSAIDs prevent, but do not reverse, neuronal cell cycle reentry in a mouse model of Alzheimer disease. J Clin Invest 119:3692-3702

219. Veld BA in t', Ruitenberg A, Hofman A et al (2001) Nonsteroidal antiinflammatory drugs and the risk of Alzheimer's disease. N Engl J Med 345:1515-1521

220. Villemagne VL, Burnham S, Bourgeat $P$ et al (2013) Amyloid $\beta$ deposition, neurodegeneration, and cognitive decline in sporadic Alzheimer's disease: A prospective cohort study. Lancet Neurol 12:357367

221. Vlad SC, Miller DR, Kowall NW, Felson DT (2008) Protective effects of NSAIDs on the development of Alzheimer disease. Neurology 70:1672-1677

222. Weggen S, Eriksen JL, Das P et al (2001) A subset of NSAIDs lower amyloidogenic Abeta42 independently of cyclooxygenase activity. Nature 414:212-216

223. Weller J, Budson A (2018) Current understanding of Alzheimer's disease diagnosis and treatment. F1000Research 7:F1000 Faculty Rev-1161

224. Whitehouse PJ, Price DL, Clark AW et al (1981) Alzheimer disease: Evidence for selective loss of cholinergic neurons in the nucleus basalis. Ann Neurol 10:122-126

225. Whitehouse PJ, Price DL, Struble RG et al (1982) Alzheimer's disease and senile dementia: Loss of neurons in the basal forebrain. Science 215:1237-1239

226. Wilhelmsson U, Bushong EA, Price DL et al (2006) Redefining the concept of reactive astrocytes as cells that remain within their unique domains upon reaction to injury. PNAS 103:17513-17518

227. Wingate RJ, Hatten ME (1999) The role of the rhombic lip in avian cerebellum development. Development 126:4395-4404

228. Wojcinski A, Lawton AK, Bayin NS et al (2017) Cerebellar granule cell replenishment postinjury by adaptive reprogramming of Nestin + progenitors. Nat Neurosci 20:1361-1370

229. Yan Q, Zhang J, Liu H, Safura Babu-Khan R, Vassar AL, Biere M, Citron GL (2003) Anti-inflammatory drug therapy alters beta-amyloid processing and deposition in an animal model of Alzheimer's disease. J Neurosci 23:7504-7509

230. Yang C-N, Shiao Y-J, Shie F-S et al (2011) Mechanism mediating oligomeric A $\beta$ clearance by naïve primary microglia. Neurobiol Dis 42:221-230

231. Yang Y, Geldmacher DS, Herrup K (2001) DNA Replication Precedes Neuronal Cell Death in Alzheimer's Disease. J Neurosci 21:2661-2668 
232. Yang Y, Mufson EJ, Herrup K (2003) Neuronal Cell Death Is Preceded by Cell Cycle Events at All Stages of Alzheimer's Disease. J Neurosci 23:2557-2563

233. Yiannopoulou KG, Anastasiou Al, Zachariou V, Pelidou SH (2019) Reasons for failed trials of diseasemodifying treatments for alzheimer disease and their contribution in recent research. Biomedicines 7:97

234. Yokel RA, Callaghan JPO (1998) An Aluminum-Induced Increase in GFAP Is Attenuated by Some Chelators. Neurotoxicol Teratol 20:55-60

235. Yoshiyama Y, Higuchi M, Zhang B et al (2007) Synapse Loss and Microglial Activation Precede Tangles in a P301S Tauopathy Mouse Model. Neuron 53:337-351

236. Yu S, Hei Y, Liu W (2018) Upregulation of seladin-1 and nestin expression in bone marrow mesenchymal stem cell transplantation via the ERK1/2 and PI3K/Akt signaling pathways in an Alzheimer's disease model. Oncol Lett 15:7443-7449

237. Zatta P, Lucchini R, Rensburg SJ van, Taylor A (2003) The role of metals in neurodegenerative processes: aluminum, manganese, and zinc. Brain Res Bull 62:15-28

238. Zhang XJ, Greenberg DS (2012) Acetylcholinesterase involvement in apoptosis. Front Mol Neurosci $5: 40$

239. Zhao C, Deng W, Gage FH (2008) Mechanisms and functional implications of adult neurogenesis. Cell 132:645-660

240. Zheng H, Youdim MBH, Fridkin M (2009) Site-Activated Multifunctional Chelator with Acetylcholinesterase and Neuroprotective-Neurorestorative Moieties for Alzheimer's Therapy. J Med Chem 52:4095-4098

241. Zhou L, Tan S, Shan Y-L et al (2016) Baicalein improves behavioral dysfunction induced by Alzheimer 's disease in rats. Neuropsychiatr Dis Treat 12:3145-3152

242. Zhu M, Wang X, Sun L et al (2018) Can inflammation be resolved in Alzheimer's disease? Ther. Adv Neurol Disord 11:PMC6088473

\section{Figures}




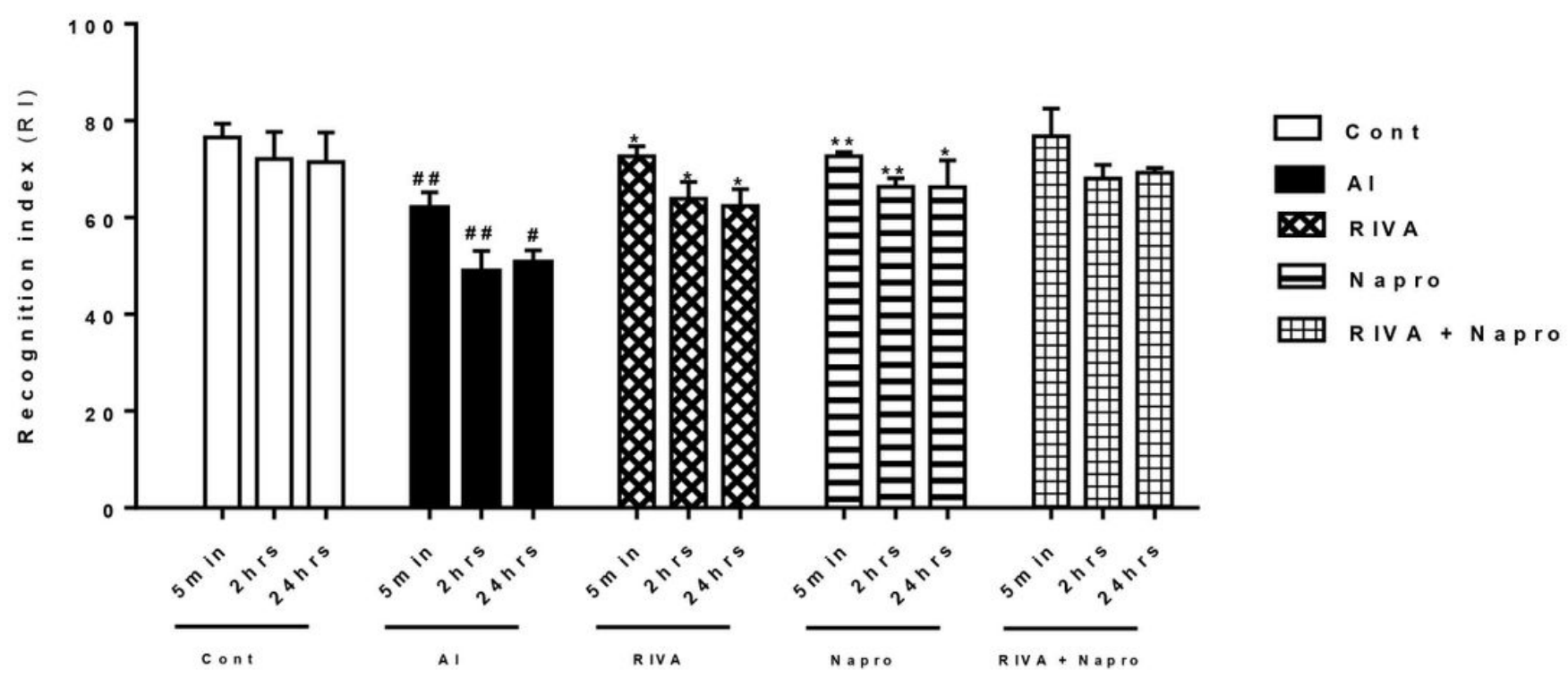

Figure 1

Effect of rivastigmine, naproxen, and their combination on recognition index (RI) of novel object recognition (NOR) test in AICl3 induced Alzheimer's in rats. The data are expressed as mean $\pm \mathrm{SEM}$. \#p, ${ }^{*} \mathrm{p}<0.05, \# \# \mathrm{p},{ }^{\star *} \mathrm{p}<0.01$. \#, \#\#: a significant difference from the Cont group. ${ }^{*}$, ${ }^{\star *}$ : a significant difference from the Al group.

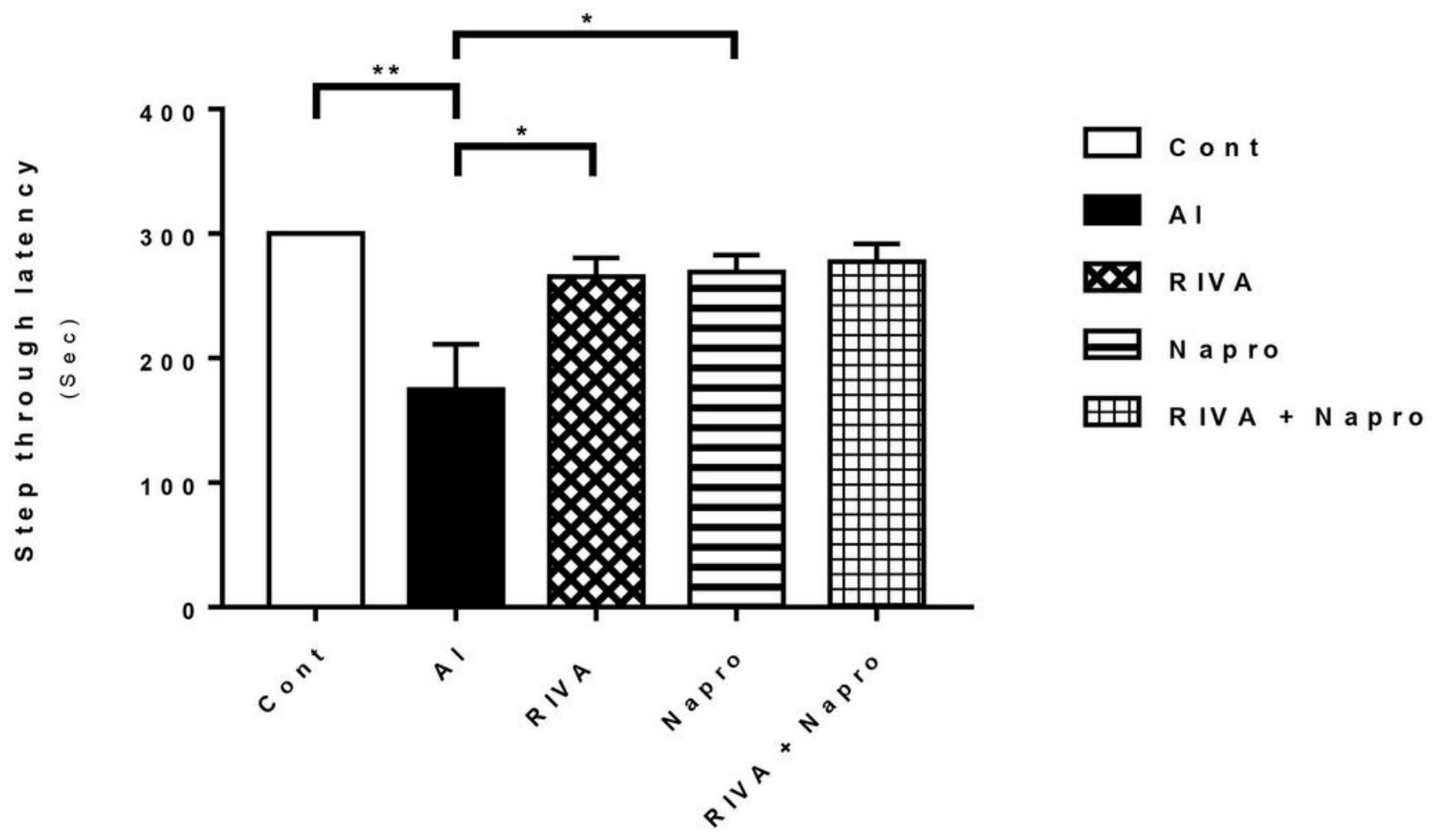

Figure 2 
Effect of rivastigmine, naproxen, and their combination on step-through latency of passive avoidance $(\mathrm{PA})$ test in $\mathrm{AlCl} 3$ induced Alzheimer's in rats. The data are expressed as mean $\pm \mathrm{SEM}$. ${ }^{\star} \mathrm{p}<0.05,{ }^{\star \star} \mathrm{p}<$ 0.01 .

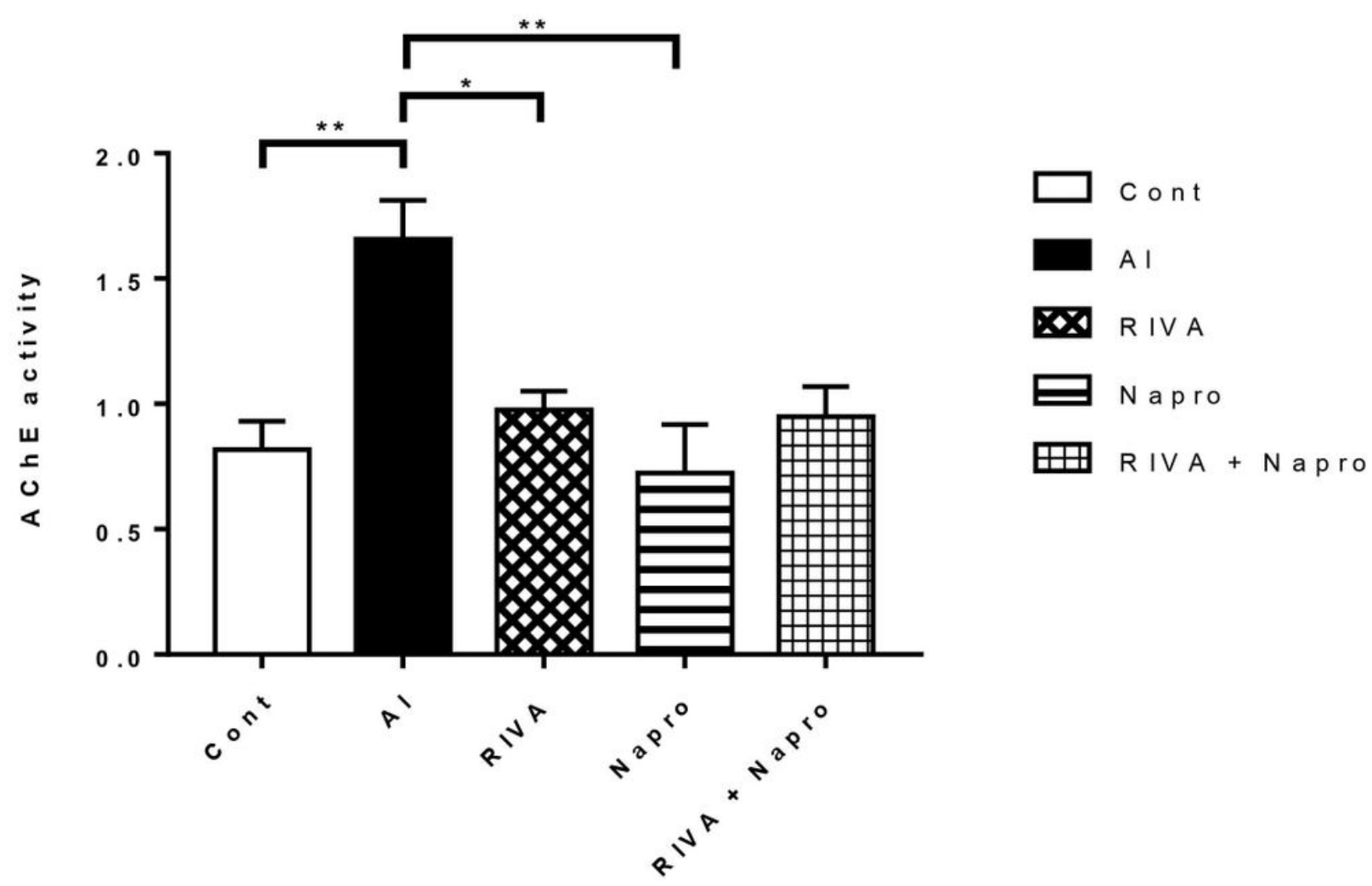

Figure 3

Effect of rivastigmine, naproxen, and their combination on hippocampal acetylcholinesterase (AChE) activity in $\mathrm{AlCl} 3$ rat model of Alzheimer disease. The data are expressed as mean $\pm \mathrm{SEM} .{ }^{*} \mathrm{p}<0.05,{ }^{*} \mathrm{p}<$ 0.01 . 

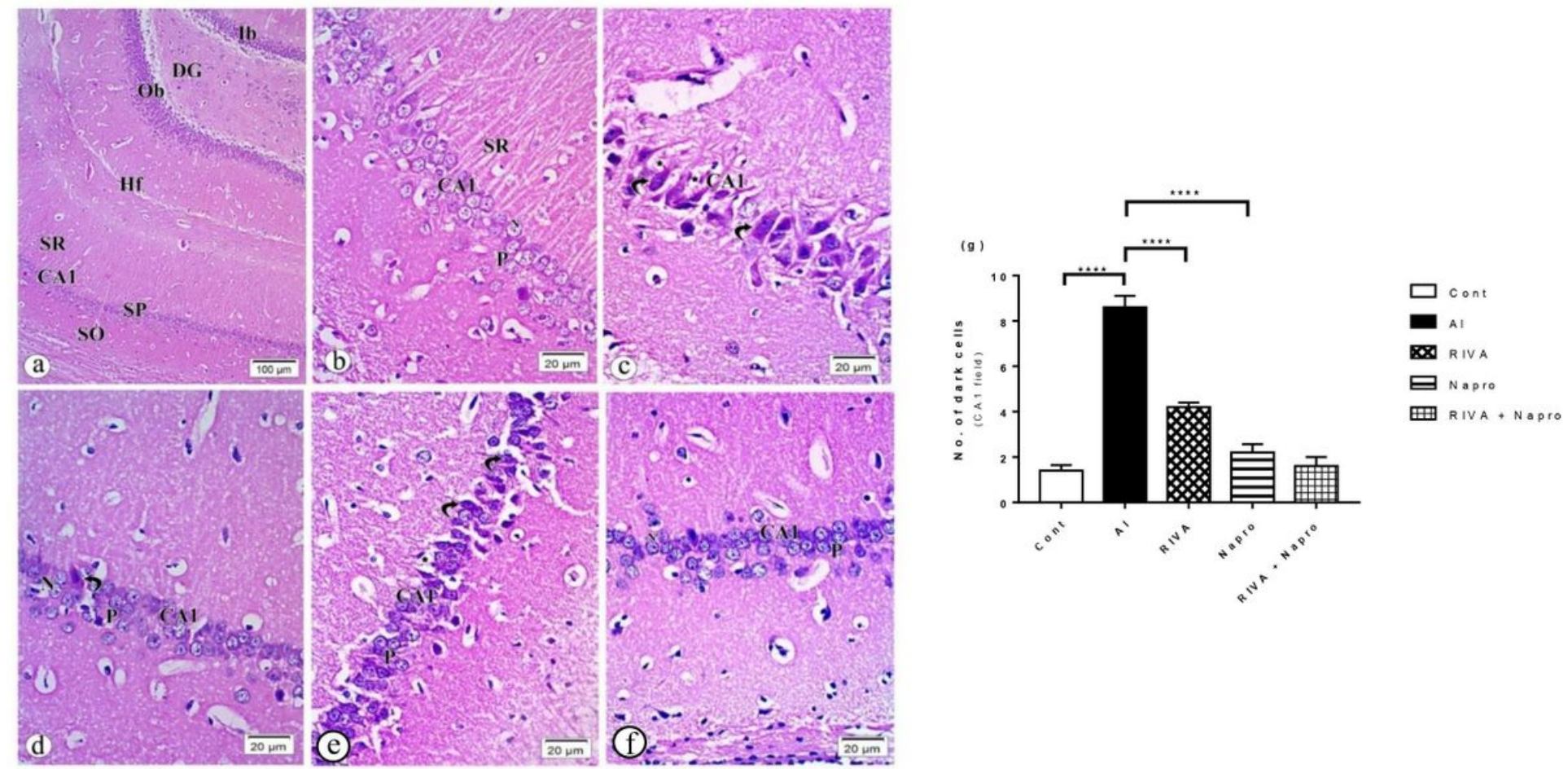

Figure 4

Photomicrographs of Hx\&E stained sections of rat hippocampus (CA1 field). a) Cont hippocampus; inner blade (Ib) and outer blade (Ob) of the dentate gyrus (DG), CA1 of Ammon's horn from alveus to hippocampal fissure (Hf), stratum oriens (SO), stratum pyramidal (SP), and stratum radiatum (SR) x100.

b) Cont CA1; medium-sized pyramidal cells $(P)$, round vesicular nuclei $(N)$, and their processes extending to stratum radiatum (SR) X400. c) Al CA1; many dark shrunken pyramidal cells (curved arrows) surrounded by empty spaces $(*)$ x400. d) RIVA CA1; most pyramidal cells $(P)$ have round vesicular nuclei $(\mathrm{N})$, few of them are still dark (curved arrows) x400. e) Napro CA1; pyramidal cells with round vesicular nuclei $(P)$ while some of them are still shrunken and deeply stained (curved arrows) x400. $f$ ) RIVA+Napro CA1; most pyramidal cells $(P)$ are well arranged and have round vesicular nuclei $(N) \times 400 . \mathrm{g})$ Statistical analysis of the number of dark cells in CA1 fields. The data are expressed as mean \pm SEM. $* \star * p<0.001$, $\star \star \star \star p<0.0001$. 


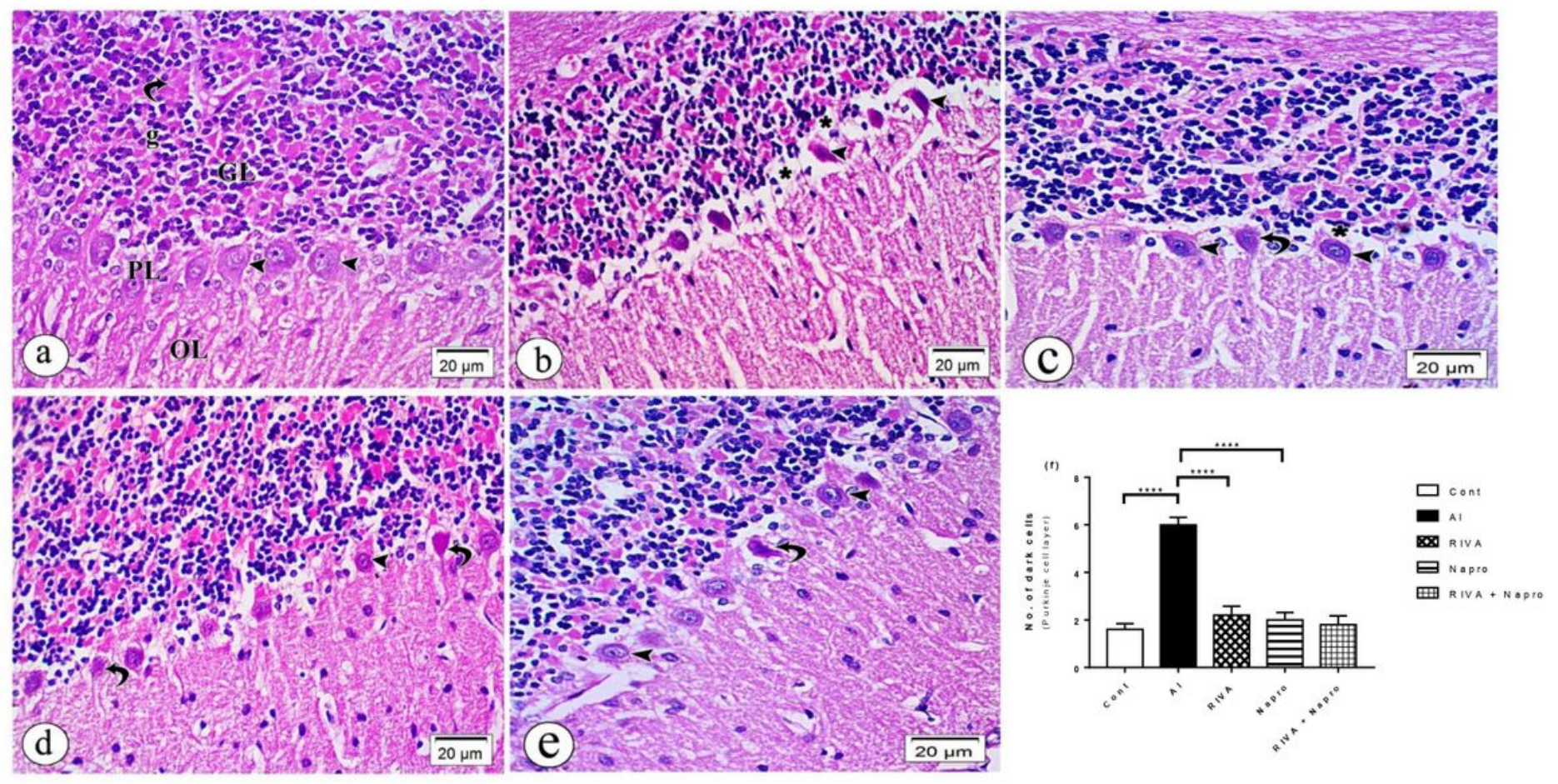

Figure 5

Photomicrographs of Hx\&E stained sections of rat cerebellum (Purkinje cell layer). a) Cont cerebellar cortex; outer molecular layer (OL), middle Purkinje cell layer (PL), and an inner granule cell layer (GL). Purkinje cells are large flask-shaped (arrowheads) with large vesicular nuclei. Granule cells (g) in clusters and separated glomeruli (curved arrows) x400. b) Al Purkinje cell layer; most of the Purkinje cells (arrowheads) are shrunken, deeply stained leaving empty spaces (*). c) RIVA Purkinje cell layer; Purkinje cells (arrowheads), few deeply stained cells are seen, empty spaces (*) x400. d) Napro Purkinje cell layer; some flask-shaped Purkinje cells (arrowheads), some irregular shrunken deeply stained cells (curved arrows). e) RIVA+Napro Purkinje cell layer; multiple flask-shaped Purkinje cells with vesicular nuclei (arrowheads), few are irregular deeply stained (curved arrows) x400. f) Statistical analysis of the number of dark cells in the Purkinje cell layer. The data are expressed as mean \pm SEM. $* \star \star * p<0.0001$. 

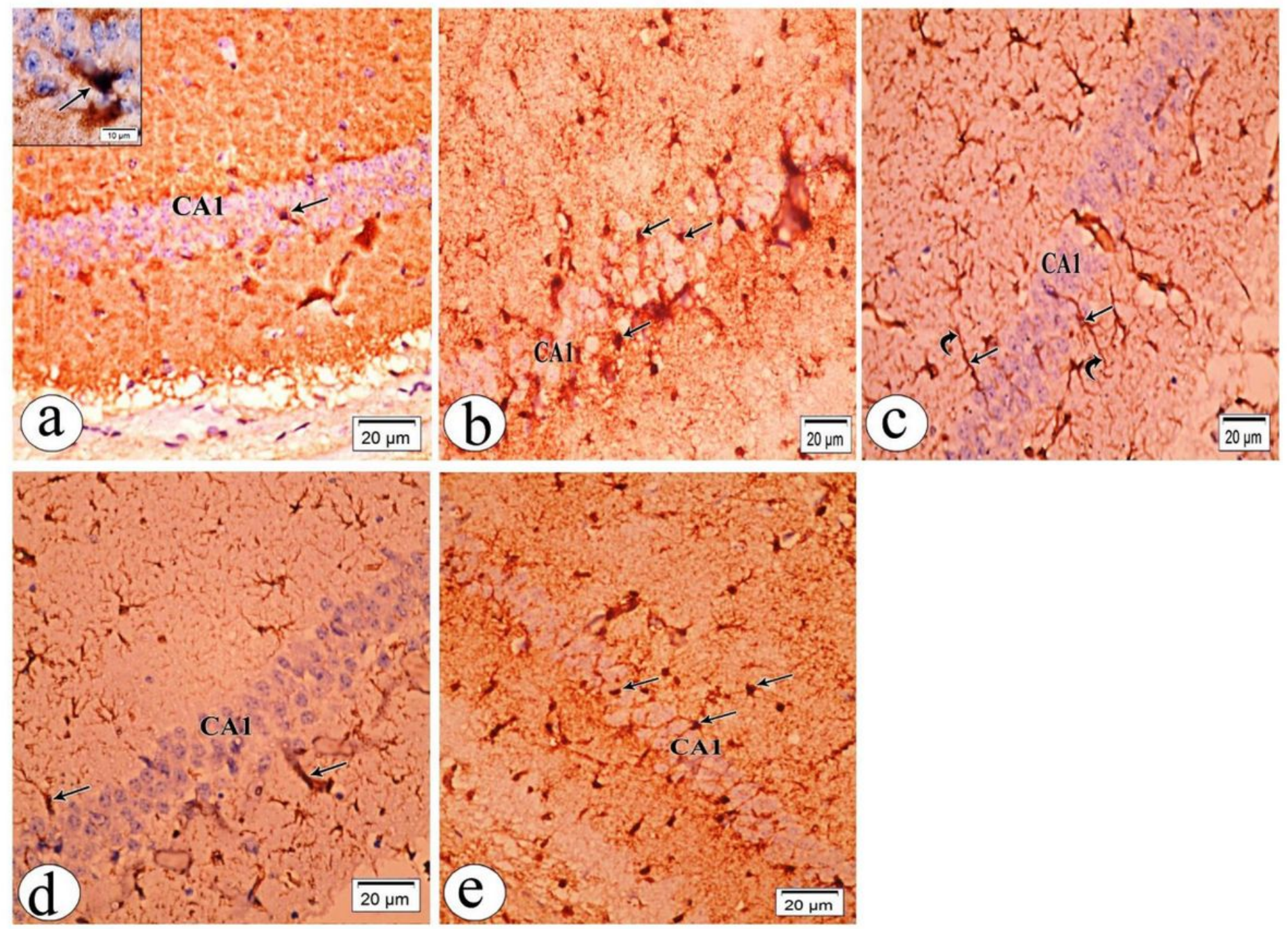

\section{Figure 6}

Photomicrographs of GFAP immunostained sections of rat hippocampus (CA1 field). a) Cont CA1; few immunostained cells $(\uparrow)$ with short processes $\times 400$, Inset: higher magnification showing glial cells with short processes $(\uparrow)$. b) Al CA1; multiple GFAP immunostained cells $(\uparrow)$ with long processes $x 400$. c) RIVA CA1; multiple GFAP immunostained cells $(\uparrow)$. d) Napro CA1; multiple GFAP immunostained cells $(\uparrow)$ with long processes $\times 400$. e) RIVA+Napro CA1; multiple GFAP immunostained cells $(\uparrow)$ x400. 

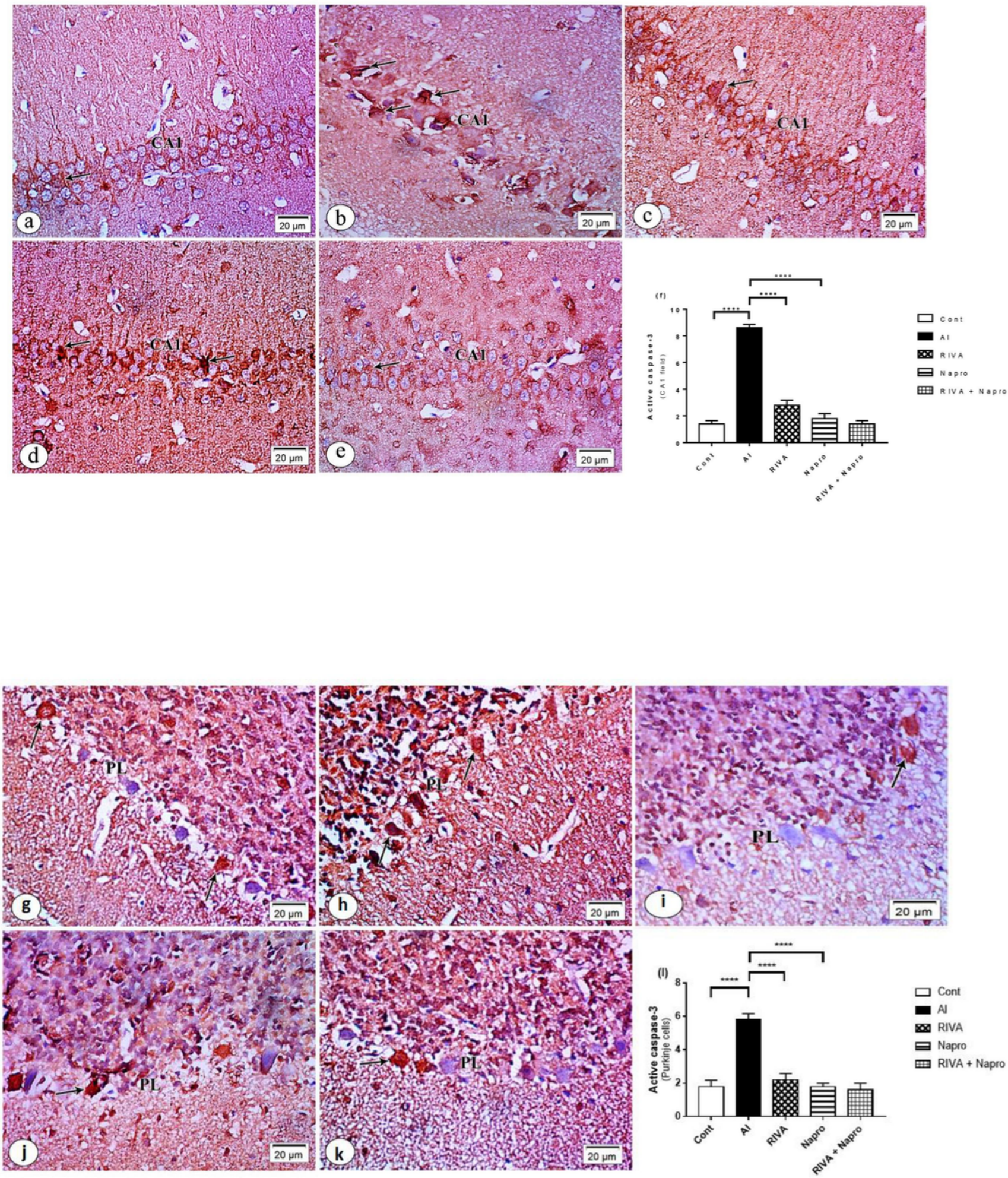

Figure 7

Photomicrographs of active caspase- 3 immunostained sections of rat hippocampus (CA1 field) and cerebellum (Purkinje cell layer). a) Cont CA1; few caspase-3 immunostained cells ( $\uparrow$ ) x400. b) Al CA1; multiple caspase- 3 immunostained cells $(\uparrow)$ x400. c) RIVA CA 1 ; few caspase- 3 immunostained cells $(\uparrow)$ x400. d) Napro CA1; few caspase-3 immunostained cells ( $\uparrow$ ) x400. e) RIVA+Napro CA1; few caspase-3 immunostained cells ( $\uparrow$ ) x400. f) Statistical analysis of the number of caspase- 3 immunostained cells in 
CA1 fields. The data are expressed as mean \pm SEM. $\left.{ }^{\star \star \star \star} p<0.0001 . \mathrm{g}\right)$ Cont Purkinje cell layer; few caspase-3 immunostained cells $(\uparrow)$. h) Al Purkinje cell layer; multiple caspase- 3 immunostained cells $(\uparrow)$. i) RIVA Purkinje cell layer; few caspase-3 immunostained cells $(\uparrow)$. j) Napro Purkinje cell layer; few caspase-3 immunostained cells $(\uparrow)$. k) RIVA+Napro Purkinje cell layer; few caspase-3 immunostained cells $(\uparrow)$. I) Statistical analysis of the number of caspase-3 immunostained cells in Purkinje cell layer. The data are expressed as mean \pm SEM. ${ }^{* \star \star \star} p<0.0001$.
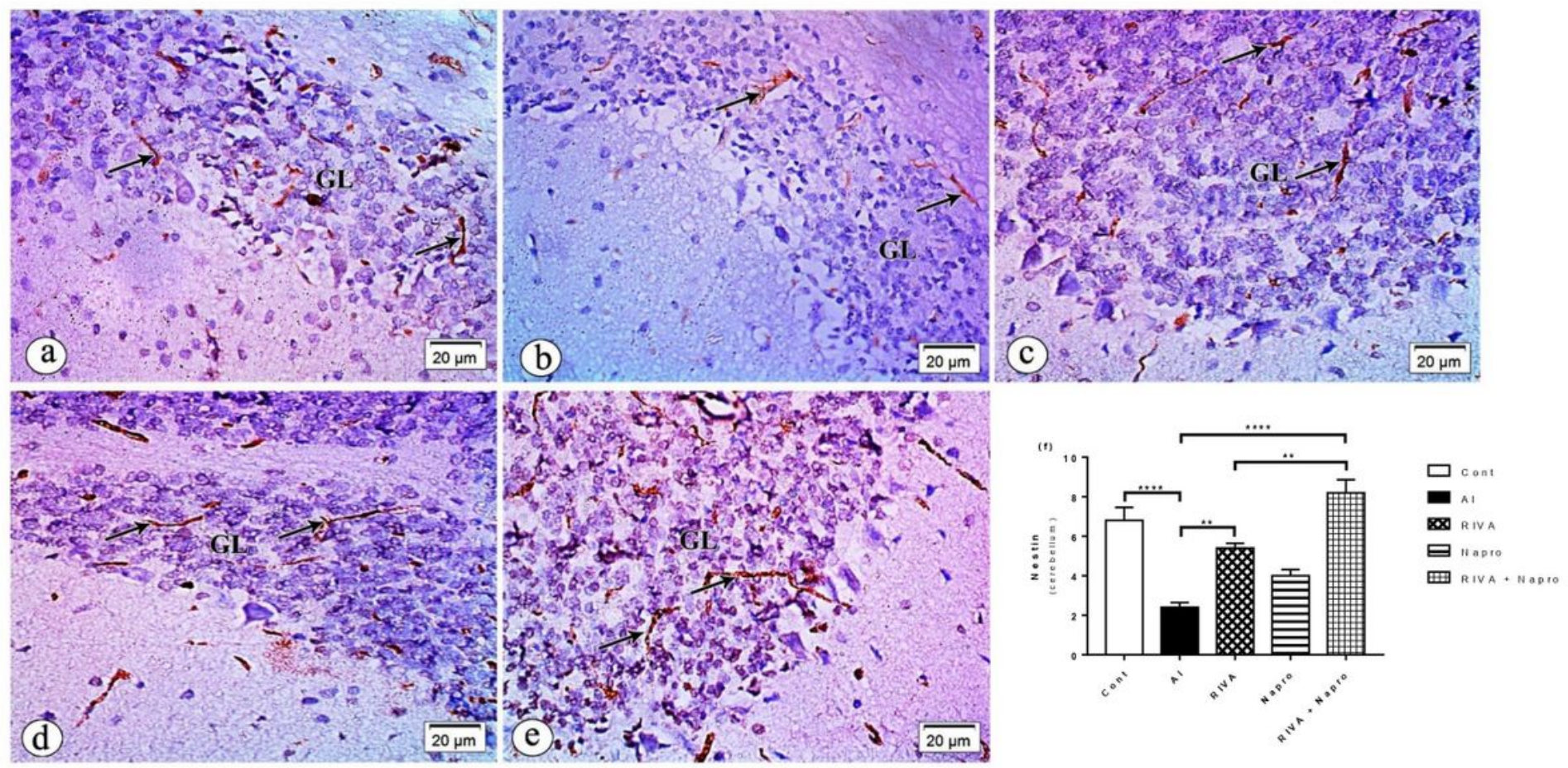

\section{Figure 8}

Photomicrographs of nestin immunostained sections of rat cerebellum. a) Cont; multiple nestin immunostained cells ( $\uparrow)$. b) Al; few nestin immunostained cells ( $\uparrow)$. c) RIVA; multiple nestin immunostained cells $(\uparrow)$. d) Napro; multiple nestin immunostained cells $(\uparrow)$. e) RIVA+Napro; multiple nestin immunostained cells $(\uparrow) \times 400$. f) Statistical analysis of the number of nestin immunostained cells in cerebellar tissues. The data are expressed as mean \pm SEM. ${ }^{\star *} p<0.01, * \star \star \star p<0.0001$. 


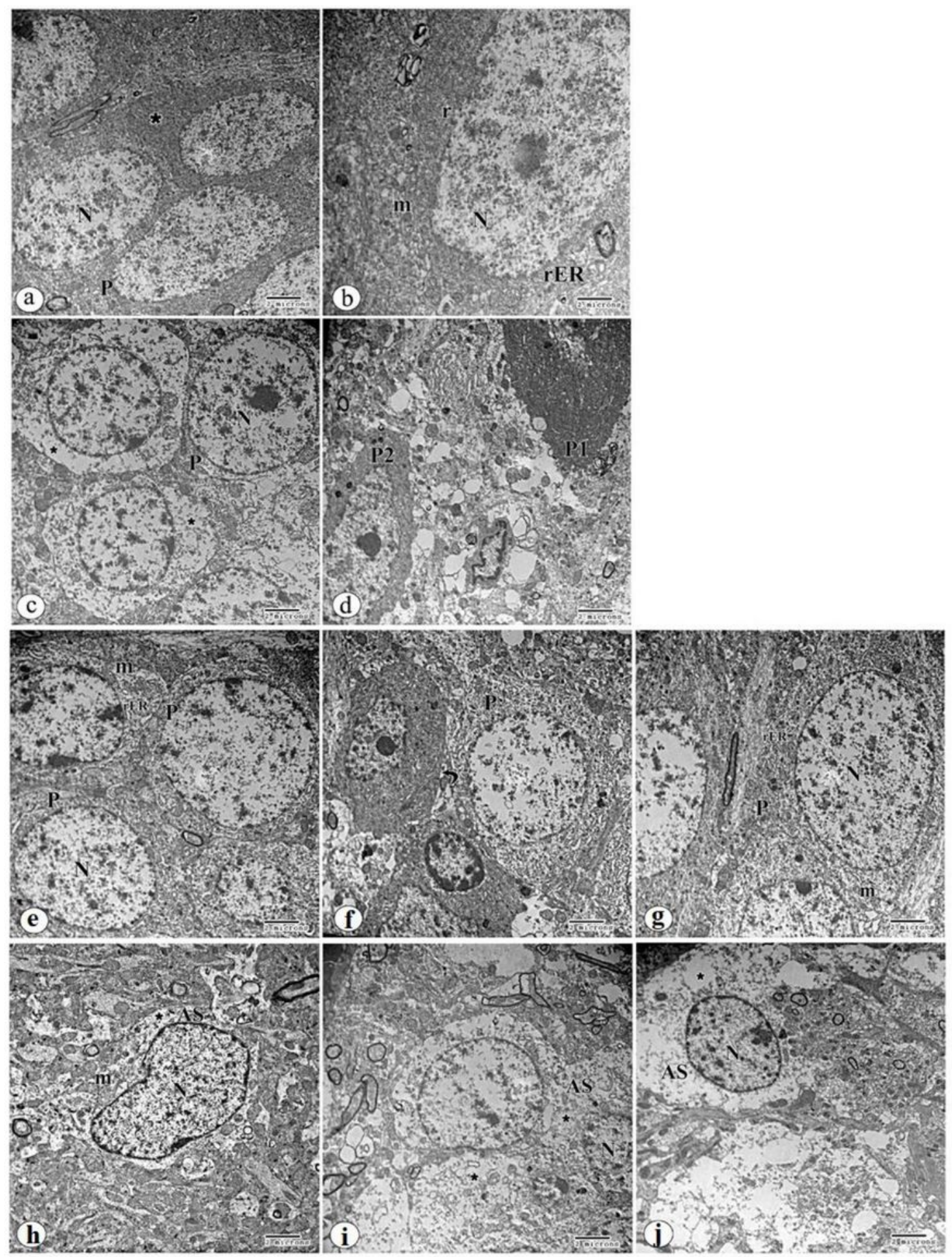

\section{Figure 9}

Transmission electron micrographs (TEM) of rat hippocampus (CA1 fields; pyramidal cells \& astrocytes). a) Cont pyramidal cells; multiple medium-sized $(\mathrm{P})$ with oval large nuclei $(\mathrm{N})$ and abundant cytoplasm (*) $x 3600$. b) Higher magnification shows abundant cytoplasm that contains mitochondria $(m)$, ribosomes $(\mathrm{r})$, and rER $\times 7200$. c) Al pyramidal cells; multiple (P) with euchromatic oval nuclei $(\mathrm{N})$ and rarefied cytoplasm (*) x3600. d) Al pyramidal cells; electron-dense irregular cells with an ill-defined nucleus (P1) 
and oval irregular nucleus (P2) x3600. e) RIVA pyramidal cells; a group of cells (P) with euchromatic oval or rounded nuclei $(\mathrm{N})$, abundant electrolucent cytoplasm that contains mitochondria $(\mathrm{m})$ and $\mathrm{rER} \times 3600$. f) Napro pyramidal cells; electrolucent cells $(P)$ and some electron-dense shrunken cells (curved arrows) x3600. g) RIVA+Napro pyramidal cells; a group of electrolucent cells $(P)$ with oval nuclei $(N)$, mitochondria $(\mathrm{m})$, and rER $\times 3600$. h) Cont astrocytes; cells $(A s)$ have a large oval nucleus $(N)$ and minimal cytoplasm $(*)$ that contain mitochondria $(\mathrm{m}) \times 3600$. i) Al astrocytes; multiple cells (AS) show electrolucent swollen cytoplasm that contains mitochondria and rounded nucleus $(N) \times 3600$. j) RIVA+Napro astrocytes; cell (AS) with swollen electrolucent cytoplasm $\left(^{*}\right)$ and large rounded nucleus (N) x3600. 

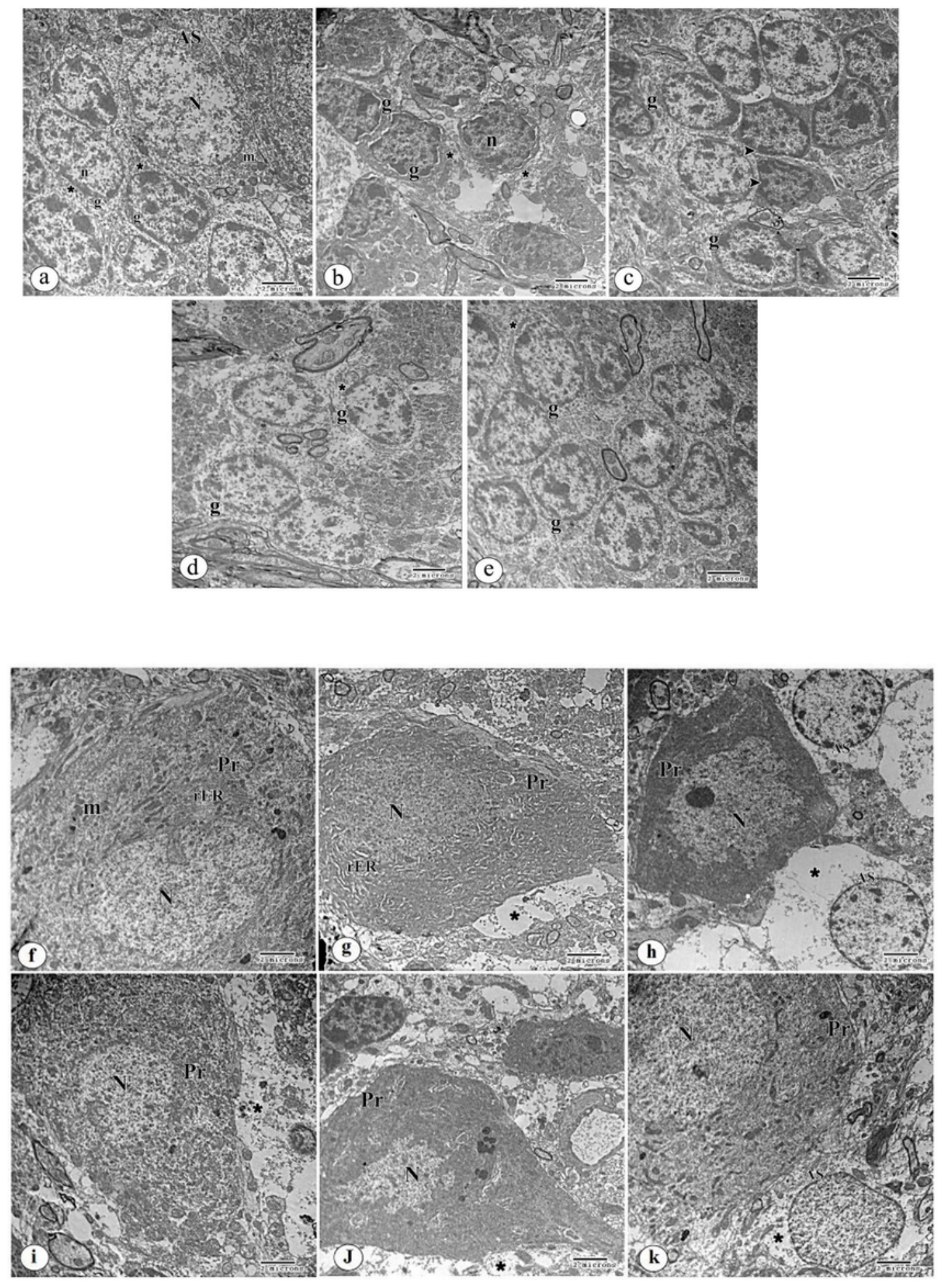

\section{Figure 10}

Transmission electron micrographs (TEM) of rat cerebellar cortex (granular \& Purkinje cell layers). a) Cont granular cell layer; multiple granule cells $(\mathrm{g})$, they have oval nuclei $(\mathrm{n})$ and minimal cytoplasm $\left({ }^{*}\right)$. Astrocyte (AS) with a large oval nucleus can be seen (N) x3600. b) Al granular cell layer; a group of granule cells (g) with heterochromatic nuclei (n) and minimal rarified cytoplasm (*). c) RIVA granular cell layer; group of granule cells with minimal electrolucent cytoplasm (g) and some still dense and 
heterochromatic nuclei (arrowheads) x3600. d) Napro granular cell layer; multiple granule cells (g) with minimal cytoplasm (*). e) RIVA+Napro granular cell layer; a group of granule cells (g) with oval nuclei and minimal cytoplasm $(*) \times 3600$. f) Cont Purkinje cell layer; Purkinje cell (Pr) perikaryon with large euchromatic nucleus $(\mathrm{N})$ and voluminous cytoplasm that contains multiple mitochondria $(\mathrm{m})$ and $\mathrm{rER}$ x3600. g) Al Purkinje cell layer; shrunken degenerated electron-dense Purkinje cell (Pr) with an ill-defined nucleus $(\mathrm{N})$ and dilated $\mathrm{rER}$, the surrounding neutrophils appear empty $(*) . h)$ Al Purkinje cell layer; shrunken degenerated electron-dense Purkinje cell (Pr) with a defined nucleus (N). Multiple Astrocytes (AS) with swollen cytoplasm $\left(^{\star}\right) \times 3600$. i) RIVA Purkinje cell layer; Purkinje cells (Pr) with defined nucleus (N) and voluminous cytoplasm $\left(^{*}\right) \times 3600$. j) Napro Purkinje cell layer; degenerated electron-dense Purkinje cells $(\operatorname{Pr})$ with a small irregular nucleus $(\mathrm{N})$ and surrounded by degenerated neutrophils $\left.\left({ }^{*}\right) . k\right)$ RIVA+Napro Purkinje cell layer; part of Purkinje cell perikaryon (Pr) with large oval euchromatic nucleus $(N)$ and electrolucent cytoplasm. Astrocyte (AS) with swollen cytoplasm $\left({ }^{*}\right)$ can be seen $\times 3600$. 